\title{
Synthesis of Redox Polymer Nanoparticles Based on Poly(vinyl catechols) and Their Electroactivity
}

\author{
Klemen Pirnat, ${ }^{*},, \neq \odot$ Nerea Casado, ${ }^{\ddagger}$ Luca Porcarelli, ${ }^{\ddagger, \S}$ Nicholas Ballard, ${ }^{\ddagger, \|}$ and David Mecerreyes ${ }^{\ddagger}, \|_{\odot}$
}

${ }^{\dagger}$ National Institute of Chemistry, Hajdrihova 19, 1000 Ljubljana, Slovenia

${ }^{\ddagger}$ POLYMAT University of the Basque Country UPV/EHU, Joxe Mari Korta Center, 20018 Donostia-San Sebastian, Spain

${ }^{\S}$ ARC Centre of Excellence for Electromaterials Science and Institute for Frontier Materials, Deakin University, 3217 Melbourne, Australia

"Ikerbasque, Basque Foundation for Science, Maria Diaz de Haro 3, E-48011 Bilbao, Spain

\section{Supporting Information}
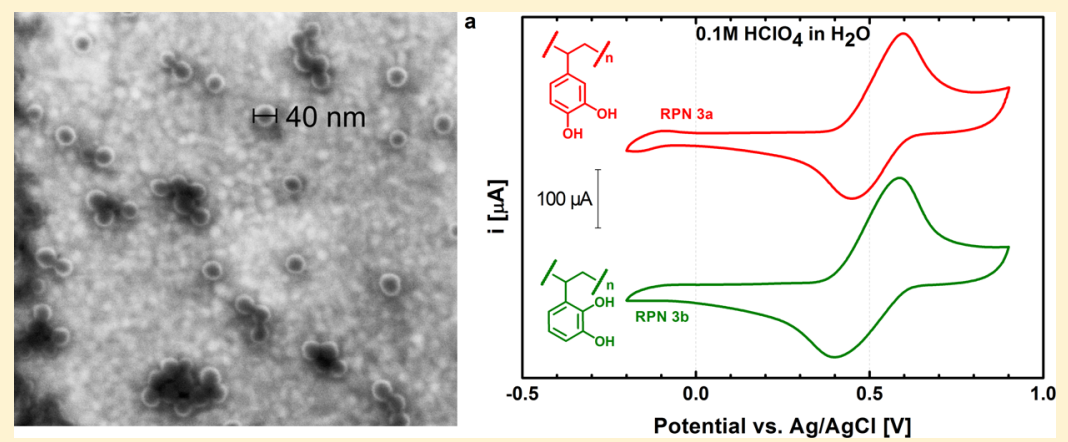

ABSTRACT: Organic materials are being investigated as an alternative to inorganic cathodes in lithium batteries with the promise of higher sustainability as well as increased theoretical capacity. Among organic materials, redox polymers based on poly(vinyl catechol) presenting the catechol/o-benzoquinone redox pair show high energy storage potential. Our main motivation in this work was to prepare polymer nanoparticles of different sizes and study their redox properties. As linear polymers are usually soluble/mechanically unstable, we prepared cross-linked polymers to maintain the size of the nanoparticles in different electrolytes. (Mini)emulsion polymerization of two dimethoxy monomers was used to synthesize spherical polymer nanoparticles cross-linked with divinylbenzene (DVB) where the size was controlled by changing the concentration of the surfactant. Deprotection yielded poly(4-vinyl catechol) and poly(3-vinyl catechol) redox active nanoparticles (RPNs) of sizes ranging between 40 and $330 \mathrm{~nm}$ as characterized by scanning electron microscopy. The electrochemical properties of the RPN were tested in aqueous- and acetonitrile-based electrolytes using cyclic voltammetry. First the effect of the nanoparticle size and the cross-linker content in the electrochemical properties was investigated. Particle size did not have a crucial effect on the electrochemistry and only the biggest $330 \mathrm{~nm}$ RPN showed slightly diminished electrochemical properties. The cross-linker had a negative effect on the maximum reduction current $(i C)$ but improved cycling stability. Based on these results we decided to use the smallest $40 \mathrm{~nm}$ nanoparticles with the lowest (1\% DVB) cross-linker content for further electrochemical testing. Both RPN isomers showed reversible behavior in aqueous acidic-, neutral-, as well as in acetonitrile-based electrolyte. Poly(4-vinyl catechol)-based RPN had slightly higher reduction potential at $0.45 \mathrm{~V}$ versus $\mathrm{Ag} / \mathrm{AgCl}\left(0.1 \mathrm{M} \mathrm{HClO}_{4}\right)$ compared to another isomer with $0.40 \mathrm{~V}$ versus $\mathrm{Ag} / \mathrm{AgCl}$. When switching from an acidic aqueous electrolyte to neutral, the redox potential was shifted $440-475 \mathrm{mV}$ to lower values. Because of their high reduction potential and theoretical capacity at $394 \mathrm{~mA} \mathrm{~h} / \mathrm{g}$ these synthetic RPNs show promising properties to be used as cathodes in a variety of batteries. However, exact capacity determination, long term cycling, testing in nonaqueous electrolytes, and redox flow batteries needs to be performed in the future.

\section{INTRODUCTION}

(Nano)particles of inorganic oxides or phosphates such as lithium nickel manganese cobalt (NMC) oxides or lithium iron phosphates are commonly used as redox active materials in cathodes of lithium batteries in mobile phones and electric vehicles. However, inorganic materials present some drawbacks such as the use of rare or toxic metals ( $\mathrm{Co}, \mathrm{V}, \mathrm{Ni}$, etc.). As an alternative, organic redox materials have been proposed which show greater sustainability as well as higher theoretical capacity values of up to $600 \mathrm{~mA} \mathrm{~h} / \mathrm{g}$, ${ }^{1}$ as compared to inorganic cathodes $(<250 \mathrm{~mA} \mathrm{~h} / \mathrm{g})$. Furthermore, organic materials are versatile and can be used in several emerging battery

Received: July 5, 2019

Revised: September 13, 2019

Published: October 18, 2019 
1. Monomer Synthesis

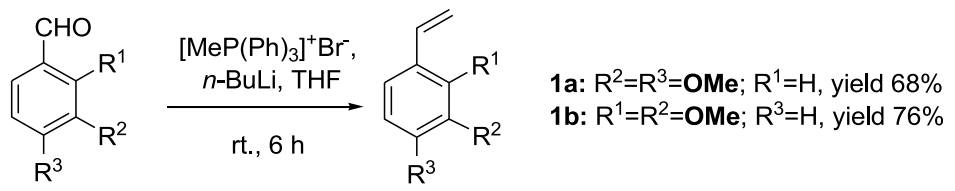

Figure 1. Wittig reaction for the preparation of protected vinyl catechols.
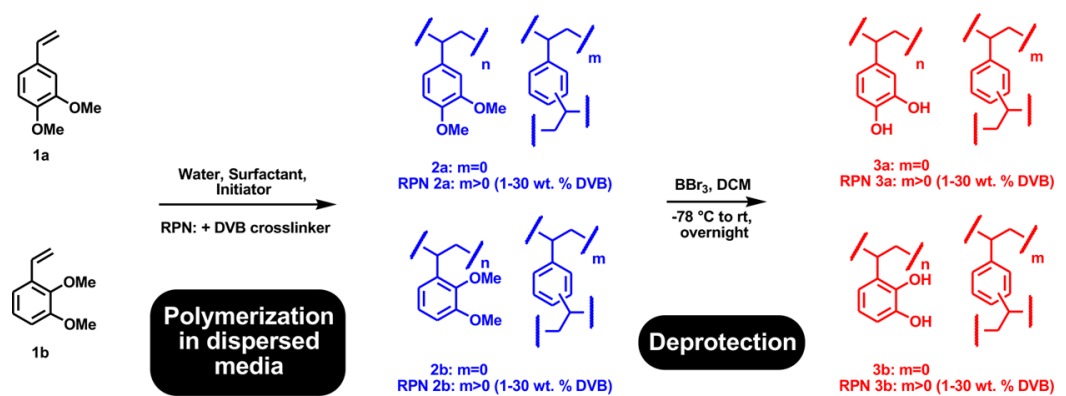

RPN $3 b: m>0$ : $m=0$

Figure 2. Reaction scheme for preparation of polymers $\mathbf{3 a}$ and $\mathbf{3 b}$ and redox active polymer nanoparticles RPN $\mathbf{3 a}$ and RPN $3 \mathbf{b}$, cross-linked with DVB.

technologies such as sodium, ${ }^{2}$ magnesium, potassium, zinc, calcium, or redox-flow batteries. When compared to inorganic redox materials, organic redox materials also offer a wider range of synthetic possibilities, easier migration of bigger/ divalent cations, as well as different redox mechanisms (conversion instead of intercalation/insertion).

However, organic materials present some disadvantages, most notably self-discharge and fast capacity fading during cycling which has historically limited their industrial use. ${ }^{3-6}$ The main reason for this is the inherent solubility of organic redox materials in organic electrolytes, which are commonly used in lithium batteries. There are several strategies to alleviate this problem such as the use of redox polymers instead of small molecules, the use of solid polymer electrolytes, grafting onto inorganic nanoparticles, or use in redox flow systems. It is worth mentioning that simple cross-linking strategies to prevent the dissolution of polymers have been under employed. ${ }^{7}$ Moreover, for good electrochemical performance other factors need to be taken into account such as the good ionic/electronic conductivity and accessibility of the redox sites. The most logical method to improve these properties is to prepare very small nanoparticles-which is a common successful method with inorganic materials such as $\mathrm{LiFePO}_{4} \cdot{ }^{8}$ Furthermore, recently the potential of redox active colloids as discrete energy storage was demonstrated in the case of redox active polymer colloids having ferrocene, nitroxide, and viologen redox sites. ${ }^{9}$ In an more recent example, the size control of zwitterionic poly(pyrrole-squarine) micro/nanospheres enhanced its performance as organic electrodes.

Redox polymers ${ }^{10,11}$ can be classified by the different redox chemistries such as (i) nitroxides/radical polymers, ${ }^{3,12}$ (ii) carbonyl polymers, ${ }^{13,14}$ (iii) sulfur-containing polymers, ${ }^{3,4}$ and (iv) semiconjugated conducting polymers. ${ }^{14,15}$ Among them, carbonyl-containing polymers, the most attractive ones are benzoquinone-containing polymers because of their high theoretical capacity (up to $496 \mathrm{~mA} \mathrm{~h} / \mathrm{g}$ ) and their high redox potential at around $2.8 \mathrm{~V}$ ( $p$-benzoquinone) until $3.0 \mathrm{~V}$ (o-quinones) versus $\mathrm{Li} / \mathrm{Li}^{+}{ }^{16-22}$ Their redox reaction in batteries consist of the reversible reduction of quinone to hydroquinone dilithium salt using two electrons and two $\mathrm{Li}^{+}$ cations which was confirmed using an in operando Fouriertransform infrared spectroscopy (FTIR) technique during battery charging/discharging. ${ }^{23}$ In a seminal work, Detrembleur and coworkers using catechol-containing linear copolymers show battery cathodes with a record energy density of $1200 \mathrm{~W} \mathrm{~h} / \mathrm{kg}$. ${ }^{19}$ Furthermore, it was recently demonstrated that catechol groups could be considered as a universal host for aqueous rechargeable batteries based on different cations from monovalent, divalent, and trivalent ones $\left(\mathrm{H}^{+}, \mathrm{Li}^{+}, \mathrm{K}^{+}, \mathrm{Zn}^{2+}\right.$, $\mathrm{Mg}^{+2}, \mathrm{Ca}^{+2}$, and $\left.\mathrm{Al}^{3+}\right)^{22}$ and can be prepared from naturally occurring ferulic acid from rice bran. ${ }^{24}$

In this article, we combined both promising strategies in the area of redox polymers, on the one side, size control of redox polymer nanoparticles and on the other side, the use of catechol redox polymers. Thus, we show here the synthesis of redox-active polymer nanoparticles (RPN) based on the catechol/o-benzoquinone redox pair. Spherical polymer particles of sizes ranging between 50 and $360 \mathrm{~nm}$ were obtained by emulsion or mini-emulsion polymerization of two dimethoxy styrene monomers and cross-linked with 1 wt $\%$ of divinylbenzene (DVB). After deprotection, poly(4-vinyl catechol), poly(3-vinyl catechol) nanoparticles were produced as confirmed by NMR and FTIR. The influence of the chemical structure and particle size in the redox properties of the polymer particles was investigated in aqueous- and acetonitrile-based electrolytes.

Monomers $\mathbf{1 a}$ and $\mathbf{1 b}$ were synthesized from corresponding aldehydes by the Wittig reaction (Figure 1) from commercial aldehydes using the modified procedure. ${ }^{25}$

\section{EXPERIMENTAL PART}

Monomer Synthesis. A solution of methyltriphenylphosphonium bromide $(58.91 \mathrm{~g}, 165 \mathrm{mmol})$ in $420 \mathrm{~mL}$ of anhydrous tetrahydrofuran (THF, 80\%) was cooled to $-20{ }^{\circ} \mathrm{C}$ and treated with of $n$-butyllithium $(2.5 \mathrm{M}$ in hexanes, $63 \mathrm{~mL}, 158 \mathrm{mmol})$. The internal temperature was maintained at -10 to $-15{ }^{\circ} \mathrm{C}$ throughout the addition. After the orange-yellow suspension was stirred at -10 ${ }^{\circ} \mathrm{C}$ for $30 \mathrm{~min}$, a solution of aldehyde $(150 \mathrm{mmol})$ in $120 \mathrm{~mL}$ of anhydrous THF was added over $30 \mathrm{~min}$ while the temperature was maintained between -5 and $-10{ }^{\circ} \mathrm{C}$. Cooling was removed, and the reaction mixture was stirred with warming to ambient temperature over $6 \mathrm{~h}$. The reaction mixture was vacuum filtered through a Buchner 
Table 1. Yield, Particle Size and PDI of RPNs before/after Deprotection

\begin{tabular}{|c|c|c|c|c|c|c|c|c|c|c|c|c|}
\hline \multirow[b]{2}{*}{ entry } & \multicolumn{8}{|c|}{ before deprotection } & \multicolumn{4}{|c|}{ after deprotection } \\
\hline & $\begin{array}{l}\text { RPN } \\
\text { name }\end{array}$ & $\begin{array}{l}\text { DVB content } \\
\text { [wt \% of } \\
\text { monomer] }\end{array}$ & $\begin{array}{l}\text { SDS content } \\
\text { [wt \% of } \\
\text { monomer] }\end{array}$ & $\begin{array}{c}\text { isolated yield } \\
\text { after } \mathrm{MeOH} \\
\text { precipitation } \\
{[\%]}\end{array}$ & $\begin{array}{l}\text { DLS size, } \\
\text { peak mean } \\
\text { intensity } \\
{[\mathrm{nm}]}\end{array}$ & $\begin{array}{l}\text { PDI by } \\
\text { DLS }\end{array}$ & $\begin{array}{l}\text { SEM } \\
\text { size } \\
{[\mathrm{nm}]}\end{array}$ & $\begin{array}{l}\text { RPN } \\
\text { name }\end{array}$ & $\begin{array}{l}\text { DLS size, } \\
\text { peak mean } \\
\text { intensity } \\
{[\mathrm{nm}]}\end{array}$ & $\begin{array}{l}\text { PDI by } \\
\text { DLS }\end{array}$ & $\begin{array}{l}\text { SEM } \\
\text { size } \\
{[\mathrm{nm}]}\end{array}$ & $\begin{array}{c}\text { isolated yield } \\
\text { after MeOH } \\
\text { precipitation } \\
{[\%]}\end{array}$ \\
\hline 1 & $2 a$ & 1 & 0.09 & 88 & 361 & 0.042 & 280 & $3 a$ & $712^{a}$ & $0.681^{a}$ & 330 & 107 \\
\hline 2 & & & 0.34 & 88 & 202 & 0.016 & 160 & & $396^{a}$ & $0.425^{a}$ & 185 & 93 \\
\hline 3 & & & 1.0 & 91 & 95 & 0.03 & 70 & & 220 & 0.222 & 105 & 105 \\
\hline 4 & & & 10 & 86 & 57 & 0.065 & 40 & & 190 & 0.405 & 40 & $>89^{d}$ \\
\hline 5 & & 5 & 10 & 88 & 55 & 0.059 & & & 560 & 0.274 & $b$ & 93 \\
\hline 6 & & 10 & 10 & 89 & 54 & 0.060 & & & 171 & 0.137 & $\sim 40$ & 92 \\
\hline 7 & & 20 & 10 & 89 & 50 & 0.063 & & & 298 & 0.240 & $\sim 40$ & 89 \\
\hline 8 & & 30 & 10 & $>83^{d}$ & 46 & 0.079 & & & 298 & 0.239 & $\sim 40$ & 89 \\
\hline 9 & $2 b$ & 1 & 8 & $82^{e}$ & 55 & 0.156 & 40 & $3 b$ & $295^{a}$ & $1.000^{a}$ & $c$ & 99 \\
\hline
\end{tabular}

${ }^{a}$ Results do not meet quality criteria: cumulant or/and multimodal error, high PDI, etc. ${ }^{b}$ Particle size could not be estimated due to agglomeration. ${ }^{c}$ No particles visible under SEM. ${ }^{d}$ Losses during the vacuum drying process (very fine powder). ${ }^{e}$ Centrifugation was used instead of filtration (see the Experimental Part).

funnel filter paper, and the filter cake was washed with hexane. The filtrate was concentrated in vacuo as viscous yellow oil which was heavily contaminated with triphenylphosphine and was difficult to remove using only chromatography. A better route was extraction with acetic acid $(\mathrm{AcOH}) /$ hexane. The hexane phase was washed 2 times with water to remove $\mathrm{AcOH}$, dried with $\mathrm{Na}_{2} \mathrm{SO}_{4}$, and evaporated in vacuo. The clear liquid was additionally purified using column chromatography using $10-30 \%$ ethyl acetate in petroleum ether.

3,4-Dimethoxystyrene (1a). mp $16.70 \mathrm{~g}$, 68\% yield, ${ }^{1} \mathrm{H}$ NMR (400 $\left.\mathrm{MHz}, \mathrm{CDCl}_{3}\right): \delta 6.95(\mathrm{~m}, 2 \mathrm{H}), 6.81(\mathrm{~d}, J=8.2 \mathrm{~Hz}, 1 \mathrm{H}), 6.65(\mathrm{dd}, J=$ $17.5,10.9 \mathrm{~Hz}, 1 \mathrm{H}), 5.61(\mathrm{~d}, J=17.6 \mathrm{~Hz}, 1 \mathrm{H}), 5.14(\mathrm{~d}, J=10.9 \mathrm{~Hz}$, $1 \mathrm{H}), 3.90(\mathrm{~s}, 3 \mathrm{H}), 3.89(\mathrm{~s}, 3 \mathrm{H}) \mathrm{ppm} .{ }^{13} \mathrm{C} \mathrm{NMR}\left(100 \mathrm{MHz}, \mathrm{CDCl}_{3}\right)$ : $\delta 149.03,149.00,136.5,130.8,119.5,111.8,111.0,108.5,56.0,55.8$ ppm. IR (ATR diamond) $\mathrm{cm}^{-1}: 3084,3000,2955,2934,2835,1631$, $1601,1580,1509,1461,1416,1393,1330,1259,1234,1154,1136$ $1023,989,898,853,809,764,613,561,543 \mathrm{~cm}^{-1}$.

2,3-Dimethoxystyrene (1b). mp $18.75 \mathrm{~g}, 76 \%$ yield, ${ }^{1} \mathrm{H}$ NMR (400 $\left.\mathrm{MHz}, \mathrm{CDCl}_{3}\right): \delta 7.15-6.99(\mathrm{~m}, 3 \mathrm{H}), 6.84(\mathrm{dd}, J=8.1,1.1 \mathrm{~Hz}, 1 \mathrm{H})$, $5.76(\mathrm{dd}, J=17.8,1.2 \mathrm{~Hz}, 1 \mathrm{H}), 5.31(\mathrm{dd}, J=11.1,1.2 \mathrm{~Hz}, 1 \mathrm{H}), 3.87$

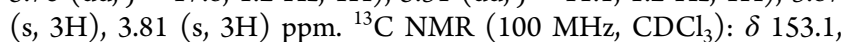
$146.8,131.9,131.3,124.1,117.9,115.2,111.7,61.0,55.9$. IR (ATR diamond) $\mathrm{cm}^{-1}: 3084,2997,2959,2934,2835,1628,1595,1574$, $1472,1429,1410,1297,1263,1221,1169,1113,1094,1067,1028$, $1001,906,808,792,745,691,574,525,482 \mathrm{~cm}^{-1}$.

Polymerization in Dispersed Media. Poly(3,4-dimethoxystyrene) (2a). Emulsion polymerization procedure was used (Figure 2). Monomer 1a $(600 \mathrm{mg}, 3.66 \mathrm{mmol})$ and sodium dodecylsulfate (SDS) ( $60 \mathrm{mg}, 10.0 \mathrm{wt} \%$ of monomer) was dispersed in $4.8 \mathrm{~mL}$ of deionized water. The reaction mixture was bubbled with nitrogen for $10 \mathrm{~min}$ and heated to $70{ }^{\circ} \mathrm{C}$, and potassium persulfate (KPS) $(3.6 \mathrm{mg}, 0.6 \mathrm{wt}$ $\%$ of monomer) solution in $200 \mu \mathrm{L}$ of deionized water was added and stirred vigorously overnight under a nitrogen atmosphere at $70{ }^{\circ} \mathrm{C}$. The next day, the dispersion of polymer nanoparticles was cooled down and the particle size by dynamic light scattering (DLS) was measured. To isolate the polymer nanoparticles, the dispersion was slowly poured in $80 \mathrm{~mL}$ of $\mathrm{MeOH}$, stirred for $15 \mathrm{~min}$ and filtered (Whatman 589/2), washed with $\mathrm{MeOH}$ two more times, and dried at room temperature (RT) overnight under vacuum. The yield was 534 $\mathrm{mg}(89 \%) .{ }^{1} \mathrm{H} \mathrm{NMR}\left(400 \mathrm{MHz}, \mathrm{CDCl}_{3}\right): \delta 6.65-6.25$ (br m, $\left.1 \mathrm{H}\right)$, 6.23-5.73 (br m, 2H), 3.84-3.68 (br s, $3 \mathrm{H}), 3.68-3.46$ (br s, $3 \mathrm{H})$, 2.00-1.57 (br m, 1H), $1.57-1.17$ (br s, $2 \mathrm{H})$ ppm. ${ }^{13} \mathrm{C}$ NMR $(100$ $\left.\mathrm{MHz}, \mathrm{CDCl}_{3}\right): \delta 149.1-147.6,147.6-146.3,139.5-136.4,120.5-$ $118.8,112.2-109.2,56.4-55.0,47.2-42.2,41.0-39.7$ ppm. IR (ATR diamond): 2996, 2915, 2832, 1604, 1589, 1506, 1462, 1448, 1417, $1256,1229,1136,1024,850,803,762,645,468 \mathrm{~cm}^{-1}$.

Poly(3,4-dimethoxystyrene) Cross-linked with 1 wt \% Poly(divinilybenzene) (RPN 2a). Poly(3,4-dimethoxystyrene) cross-linked with 1 wt \% poly(divinilybenzene) (RPN 2a) was prepared in a similar manner as polymer 2a with the only difference that DVB (6 $\mathrm{mg}, 1 \mathrm{wt} \%$ of monomer) was added to the monomer first, followed by SDS, and water addition (Figure 2). To obtain different particle sizes from 342 to $54 \mathrm{~nm}$, different amounts of SDS (0.09-10.0 wt \% of monomer) were used (Table 1). The yield varied with the SDS concentration and was in the range 521-551 mg (86-91\%). Because of cross-linking, the polymer nanoparticles were not soluble in organic solvents and NMR was not performed. To characterize the product, infrared (IR) spectroscopy was used and spectra were identical to polymer $\mathbf{2 a}$.

Poly(2,3-dimethoxystyrene) (2b). This monomer was more difficult to polymerize and KPS initiator did not work. Initiator $2,2^{\prime}$-azobis (2-methylpropionamidine)dihydrochloride (AIBA) gave only moderate conversion $(\sim 70 \%)$. The best results were obtained using a mini-emulsion polymerization technique, where monomer dispersion was preformed before polymerization: monomer $\mathbf{1 b}(600$ $\mathrm{mg}, 3.66 \mathrm{mmol}$ ) and the SDS surfactant ( $48 \mathrm{mg}, 8 \mathrm{wt} \%$ of monomer) were dispersed in $4.8 \mathrm{~mL}$ of deionized water. To prepare stable monomer emulsion, an ultrasound finger (amplitude 100\%, 50\% cycle) was used for $10 \mathrm{~min}$ using a $20{ }^{\circ} \mathrm{C}$ cooling bath (not an ice bath, as at lower $\mathrm{T}$ monomer solidifies). Then, it was bubbled with nitrogen for $10 \mathrm{~min}$, heated to $80{ }^{\circ} \mathrm{C}$, and AIBA $(3.6 \mathrm{mg}$, $0.6 \mathrm{wt} \%$ of monomer) solution in $200 \mu \mathrm{L}$ of deionized water was added and stirred vigorously overnight under a nitrogen atmosphere at $80{ }^{\circ} \mathrm{C}$. The next day, the dispersion of polymer nanoparticles was cooled down and the particle size by DLS was measured. To isolate pure polymer nanoparticles, the dispersion was slowly poured in $80 \mathrm{~mL}$ of $\mathrm{MeOH}$ and stirred for $15 \mathrm{~min}$. Filtration was not possible and centrifugation was used instead $\left(10000 \mathrm{rpm}, 1 \mathrm{~h}, 15{ }^{\circ} \mathrm{C}\right)$. The precipitate was dispersed in $\mathrm{MeOH}$ and subsequently centrifuged two more times. The resulting gel was dried under vacuum overnight to obtain a white powder (yield $468 \mathrm{mg}, 78 \%$ ). ${ }^{1} \mathrm{H}$ NMR $(400 \mathrm{MHz}$, $\mathrm{CDCl}_{3}$ ): $\delta 7.15-6.12$ (br m, 3H), 3.93-2.71 (br m, 6H), 2.71-2.27 (br m, 1H), 2.00-1.06 (br m, 2H) ppm. ${ }^{13} \mathrm{C} \mathrm{NMR} \mathrm{(100} \mathrm{MHz,}$ $\left.\mathrm{CDCl}_{3}\right): \delta 153.2-152.0,148.0-146.4,140.8-138.8,124.5-122.5$, 121.3-118.7, 111.0-108.4, 60.9-58.5, 56.8-54.9, 46.8-41.6, 33.3$30.5 \mathrm{ppm}$. IR (ATR diamond): 2932, 2832, 1582, 1471, 1428, 1262, 1216, 1166, 1093, 1055, 1007, 866, 783, $743 \mathrm{~cm}^{-1}$.

Poly(2,3-dimethoxystyrene) Cross-linked with 1 wt \% Poly(divinilybenzene) (RPN $2 b$ ). Poly(2,3-dimethoxystyrene) cross-linked with 1 wt \% poly(divinilybenzene) (RPN $2 \mathbf{b}$ ) was prepared in a similar manner as polymer $\mathbf{2 b}$ with the only difference that DVB (6 $\mathrm{mg}, 1 \mathrm{wt} \%$ of monomer) was added to the monomer first, followed by SDS, and water addition. The yield was $497 \mathrm{mg}(82 \%)$. Because of cross-linking, the polymer nanoparticles were not soluble in organic solvents and NMR was not performed. To characterize the product, IR spectroscopy was used and spectra were identical to polymer $\mathbf{2 b}$.

Deprotection Reaction. Procedure for Preparation of Dihydroxy Polymers (3a, RPN 3a, 3b, and RPN 3b). Polymer 
nanoparticles (492 mg, $3 \mathrm{mmol}$ ) were dispersed in $30 \mathrm{~mL}$ of anhydrous dichloromethane (DCM) using an ultrasound bath for 15 min, until all the material was dispersed (Figure 2). Then it was stirred for an additional $1 \mathrm{~h}$ and cooled to $-70{ }^{\circ} \mathrm{C}$, followed by the slow addition of $1 \mathrm{M}$ solution of $\mathrm{BBr}_{3}(7.5 \mathrm{~mL}, 7.5 \mathrm{mmol}, 2.5$ equiv) in anhydrous DCM. After addition, the reaction mixture was left to warm to RT and stirred overnight. The next day the reaction mixture was cooled again to $-50{ }^{\circ} \mathrm{C}$ and the reaction was cautiously quenched by slow addition of $\mathrm{MeOH}(2.4 \mathrm{~mL}, 1.9 \mathrm{~g}, 59 \mathrm{mmol})$. It was left to warm again to RT and poured into $30 \mathrm{~mL}$ of ice cold water, stirred for additional $1 \mathrm{~h}$, filtered (Whatman 589/2), and washed two more times with cold water; the resulting poly(catechols) tend to stick strongly to filter paper. To separate gelatinous polymer and filter, the paper was wetted with few drops of EtOH. The product was freezedried overnight to obtain a porous white material.

Poly(3,4-dihydroxystyrene) (3a). mp $424 \mathrm{mg}$ (104\% crude yieldtraces of water), ${ }^{1} \mathrm{H}$ NMR $\left(400 \mathrm{MHz}\right.$, acetone- $\left.d_{6}\right): \delta 6.79-5.72(\mathrm{br}$ $\mathrm{m}, 3 \mathrm{H}$ ), $2.23-1.72$ (br m, $1 \mathrm{H}), 1.72-1.09$ (br m, $2 \mathrm{H})$ ppm. ${ }^{13} \mathrm{C}$ NMR $\left(400 \mathrm{MHz}\right.$, acetone- $\left.d_{6}\right): \delta 145.6-144.3,143.8-142.6,140.0-$ 137.9, 121.5-119.2, 116.8-113.9, 48.7-42.7, 41.4-39.7 ppm. IR (ATR diamond): 3261 (br), 2917, 2844, 1602, 1509, 1439, 1357, $1274,1241,1180,1105,930,862,809,778,723,635,588,439,406$ $\mathrm{cm}^{-1}$

Cross-linked Poly(3,4-dihydroxystyrene) (RPN 3a). mp $396 \mathrm{mg}$ ( $97 \%$ yield). Because of cross-linking, the polymer nanoparticles were not soluble in organic solvents and NMR was not performed. To characterize the product, IR spectroscopy was used and spectra were identical to polymer $3 \mathrm{a}$.

Poly(2,3-dihydroxystyrene) (3b). mp $418 \mathrm{mg}$ (102\% crude yieldtraces of water), ${ }^{1} \mathrm{H}$ NMR ( $\left.400 \mathrm{MHz}, \mathrm{MeOH}-d_{4}\right): \delta 6.74-5.88$ (br m, $3 \mathrm{H}), 2.72-2.11$ (br m, 1H), $1.88-1.21$ (br m, $2 \mathrm{H})$ ppm. ${ }^{1} \mathrm{H}-{ }^{13} \mathrm{C}$ CPMAS NMR (400-100 MHz): $\delta 143,132,120,113,41,32 \mathrm{ppm}$. IR (ATR diamond): 3380 (br), 2927, 2856, 1617, 1593, 1473, 1274, 1178, 1066, 927, 898, 824, 781, $732 \mathrm{~cm}^{-1}$.

Cross-linked Poly(2,3-dihydroxystyrene) (RPN 3b). mp $404 \mathrm{mg}$ ( $99 \%$ yield). Because of cross-linking, the polymer nanoparticles were not soluble in organic solvents and NMR was not performed. To characterize the product, IR spectroscopy was used and spectra were identical to polymer $\mathbf{3 b}$.

Apparatuses Used. Dynamic Light Scattering. DLS was measured with a Malvern Zetasizer Nano ZS. Usually a small drop of the reaction mixture ( $\sim 10 \mathrm{wt} \%$ polymer dispersion in water) was diluted with $1 \mathrm{~mL} \mathrm{MQ}$.

Scanning Electron Microscopy. SEM (scanning electron microscopy) was done with a JEOL JSM-7000F microscope. A droplet of the particle suspension was put on a gold-coated glass holder and left to dry. To obtain the secondary electron images, $5 \mathrm{kV}$ was used and beam current was about $0.01 \mathrm{nA}$.

Nuclear Magnetic Resonance. Liquid ${ }^{1} \mathrm{H}$ and ${ }^{13} \mathrm{C}$ NMR spectra were recorded in a $400 \mathrm{MHz}$ Bruker spectrometer. Deuterated solvents $\mathrm{CDCl}_{3}, \mathrm{MeOH}-d_{4}$, and acetone- $d_{6}$ were used; and shifts were corrected according to their solvent peaks. ${ }^{26}$

${ }^{1} \mathrm{H}-{ }^{13} \mathrm{C}$ CPMAS NMR. ${ }^{1} \mathrm{H}-{ }^{13} \mathrm{C}$ CPMAS NMR spectra were recorded on a $400 \mathrm{MHz}$ Bruker system equipped with a $4 \mathrm{~mm}$ MASDVT TRIPLE Resonance HYX MAS probe. Larmor frequencies were 400.17 and $100.63 \mathrm{MHz}$ for ${ }^{1} \mathrm{H}$ and ${ }^{13} \mathrm{C}$ nuclei, respectively. Chemical shifts were reported relative to the signals of ${ }^{13} \mathrm{C}$ nuclei in GLYCIN. Sample rotation frequency was $12 \mathrm{kHz}$ and relaxation delay was 5 s. Polarization transfer was achieved with RAMP crosspolarization (ramp on the proton channel) ${ }^{27}$ with a contact time of 5 ms. High-power SPINAL 64 heteronuclear proton decoupling was applied during acquisition. ${ }^{28}$

Infrared. IR spectra were measured on a Bruker Alpha II spectrophotometer using a Platinum ATR module with diamond window.

Gel Permeation Chromatography. Gel permeation chromatography (GPC) analysis was performed on a Shimadzu LC-20AD pump with an IR detector (Waters 2410 differential refractometer), with a Styragel HR series of columns (HR6-HR4-HR2). The analyses were performed at $35{ }^{\circ} \mathrm{C}$ and THF was used as a mobile phase at a flow rate of $1 \mathrm{~mL} \mathrm{~min}^{-1}$. Calibration relative to polystyrene standards (PS $28770 \mathrm{~g} \mathrm{~mol}^{-1}$; Polymer Labs) was used to calculate molecular weights and polydispersity (PDI).

Thermogravimetric Analysis. The thermal stability of the samples was investigated by the thermogravimetric analysis (TGA) performed on a TGA Q500 from TA Instruments. Measurements were carried out by heating the sample at $10{ }^{\circ} \mathrm{C} / \mathrm{min}$ under a nitrogen atmosphere from RT to $800{ }^{\circ} \mathrm{C}$.

Differential Scanning Calorimetry. Differential scanning calorimetry (DSC) measurements were carried out on a DSC Q2000 from TA Instruments. The DSC scans were performed at heating and cooling rates of $10{ }^{\circ} \mathrm{C} / \mathrm{min}$ from -25 to $200{ }^{\circ} \mathrm{C}$ (samples $3 \mathrm{a}$ and $3 \mathbf{b}$ were heated to $180^{\circ} \mathrm{C}$ ). The second heating scan is reported here.

Electrochemistry. The electrochemical characterization was carried out on an Autolab PGSTAT204 potentiostat, using a three-electrode configuration. Platinum wire and a glassy carbon (GC) electrode (with an area of $0.07 \mathrm{~cm}^{2}$ ) were used as the counter electrode (CE) and working electrode, respectively. For the reference electrode, $\mathrm{Ag}$ / $\mathrm{AgCl}(\mathrm{KCl} 3 \mathrm{M})$ was used in aqueous electrolytes $\left(0.1 \mathrm{M} \mathrm{HClO}_{4}\right.$ and $0.1 \mathrm{M}$ LiTFSI). For nonaqueous electrolytes, the $\mathrm{Ag} / \mathrm{Ag}^{+}$reference electrode was used, filled with $0.01 \mathrm{M} \mathrm{AgNO}_{3}$, and $0.1 \mathrm{M}$ tetrabutylammonium hexafluorophosphate $\left(\mathrm{TBAPF}_{6}\right)$ in anhydrous acetonitrile. Polymer nanoparticles $(60 \mathrm{mg})$, carbon black SC65 (30 $\mathrm{mg}$ ), and $1 \mathrm{~mL}$ of $1 \mathrm{wt} \%$ solution of polyvinylidene fluoride (PVDF) in $N$-methylpyrrolidone were dispersed using an ultrasound bath for $15 \mathrm{~min}$. The final composition of the electrode was $60 \mathrm{wt} \%$ of the active material, 30 wt \% carbon black, and 10 wt \% of PVDF. Dispersions were stirred for additional $2 \mathrm{~h}$ using a magnetic stirrer. Deprotected polymer dispersions were stored in the fridge to prevent oxidation with air atmosphere. Then, $3 \mu \mathrm{L}$ of dispersion was dropped on the top of the GC electrode and dried overnight at RT. Before cyclic voltammetry (CV) experiments, the electrochemical cell with the electrolyte was bubbled with nitrogen for $15 \mathrm{~min}$, and then the electrochemical tests were conducted.

\section{RESULTS AND DISCUSSION}

Synthesis and Characterization of Linear Poly(vinyl catechol)s. In order to validate our synthetic approach, first linear polymer nanoparticles were synthesized (Figure 2) by miniemulsion polymerization of two different protected vinylcatechol monomers such as 3,4- and 2,3-dimethoxystyrene (polymers $\mathbf{1 a}$ and $\mathbf{1 b}$ ). Use of protected monomers is crucial to enable radical polymerization and to prevent uncontrolled cross-linking as free catechols are known radical inhibitors. ${ }^{29}$ For the polymerization of 3,4-dimethoxystyrene, emulsion polymerization was used and for 2,3-dimethoxystyrene slightly different mini-emulsion conditions were used to improve the yield of the polymerization. After isolation of the poly(dimethoxy styrene) polymers, an additional deprotection step was needed to remove the methyl groups to obtain redoxactive catechol groups leading to poly(4-vinyl catechol) (3a) and poly(3-vinyl catechol) (3b).

Linear polymers $\mathbf{2 a}$ and $\mathbf{2 b}$ were characterized by NMR and GPC. Polymer 2a showed a typical high molecular weight $M_{\mathrm{w}}$ close to $900000 \mathrm{~g} / \mathrm{mol}$ and dispersity 2.39. Polymer $\mathbf{2 b}$ prepared by mini-emulsion polymerization presented lower molecular weight close to $M_{\mathrm{w}}=500000 \mathrm{~g} / \mathrm{mol}$ and a very high dispersity of 8.4. GPC chromatograms are included in the Supporting Information (Figure S1). The polymerization was corroborated by ${ }^{1} \mathrm{H}$ NMR as vinyl peaks (three signals from 7 to $5 \mathrm{ppm}$ ) disappeared (Figure 3a,b). The resulting polymers $\mathbf{2 a}$ and $\mathbf{2 b}$ showed broad peaks which is typical for polymers, and new peaks were formed in the alkyl region $(2.8-1.0 \mathrm{ppm})$ because of the formation of the polymer aliphatic chain. In ${ }^{13} \mathrm{C}$ NMR, because of similar chemical shifts of the vinyls and aromatics, it is more difficult to notice the disappearance of 


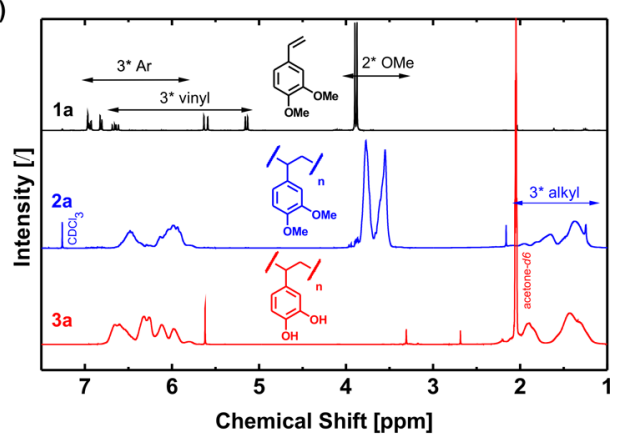

b)

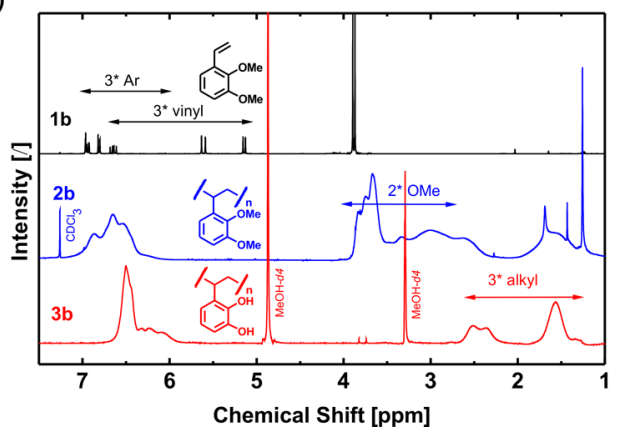

Figure 3. ${ }^{1} \mathrm{H}$ NMR spectra of: (a) 1a, 2a, and $\mathbf{3 a}$ and (b) $\mathbf{1 b}, \mathbf{2} \mathbf{b}$, and 3 b.

vinyl carbons (Figure S2a,b). On the other hand, formation of alkyl carbons $(50-30 \mathrm{ppm})$ is clearly visible. After the deprotection reaction (polymers $3 \mathbf{a}$ and $\mathbf{3 b}$ ), methoxy peaks disappeared and phenol groups were formed which is clearly visible from ${ }^{1} \mathrm{H}$ NMR (4.0-2.8 ppm) and also in ${ }^{13} \mathrm{C}$ NMR (65-50 ppm).

The chemical transformations during the polymerization and deprotection reactions were also followed by FTIR spectra. As seen in Figure $4 \mathrm{a}$, characteristic vinyl vibrations for monomer 1a are at $1631 \mathrm{~cm}^{-1}\left(\mathrm{C}=\mathrm{C}\right.$ stretching), 989 and $898 \mathrm{~cm}^{-1}$ (out-of-plane $\mathrm{C}-\mathrm{H}$ vibrations), and 613,561 , and $543 \mathrm{~cm}^{-1}$ ( $\mathrm{C}=\mathrm{C}$ skeletal vibrations). During polymerization reaction, the vinyl group is converted into the polymer chain and in polymer 2a these vinyl peaks disappear. Characteristic peaks at $1256,1229,1136$, and $1024 \mathrm{~cm}^{-1}$ (symmetric and asymmetric $\mathrm{Ar}-\mathrm{O}-\mathrm{Me}$ stretching) are replaced during the deprotection reaction with peaks at $3200(\mathrm{O}-\mathrm{H}$ stretch), 1273 and 1175 $\mathrm{cm}^{-1}$ (O-H and $\mathrm{C}-\mathrm{O}$ stretching combination). Similar features are observed in the case of isomer $3 \mathbf{b}$ (Figure $4 b$ ). If we compare both polymers $3 \mathbf{a}$ and $\mathbf{3 b}$, we can notice characteristic broad peaks at $3200-3380 \mathrm{~cm}^{-1}$ (O-H stretch), $1175-1286 \mathrm{~cm}^{-1}(\mathrm{O}-\mathrm{H}$ and $\mathrm{C}-\mathrm{O}$ stretching combination), and different patterns in out-of-plane aromatic $\mathrm{C}-\mathrm{H}$ vibrations (Figure S3). Polymer 3a shows a peak at $779 \mathrm{~cm}^{-1}$, which is typical for the asymmetric tri-substituted benzene ring. Polymer $3 \mathbf{b}$ shows two peaks at 781 and $732 \mathrm{~cm}^{-1}$ typical for vicinal tri-substituted benzene.

The thermal properties of the polymers were characterized by TGA and DSC. TGA measurements showed an interesting mass drop pattern (Figure 5a). Protected polymers $\mathbf{2 a}$ and $\mathbf{2} \mathbf{b}$ were stable until 270 and $315^{\circ} \mathrm{C}$, and then fast degradation occurred. At $435^{\circ} \mathrm{C}$, both polymers already almost completely degraded (93-97\% mass loss). We were not investigating the mechanism but probably thermal de-polymerization occurred which is known for polystyrenes. ${ }^{30}$ Deprotected polymers 3a and $\mathbf{3 b}$ showed an observable mass drop below their

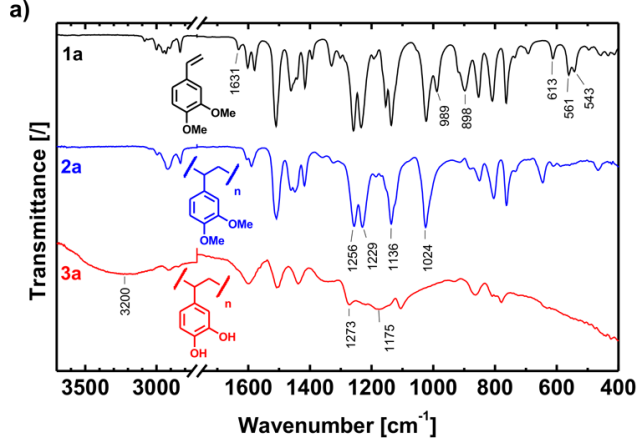

b)

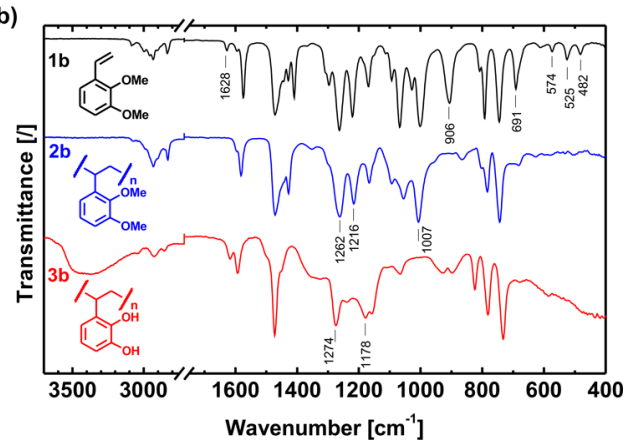

Figure 4. IR spectra of compounds: (a) 1a, 2a, 3a and (b) 1b, 2b, and 3 b.
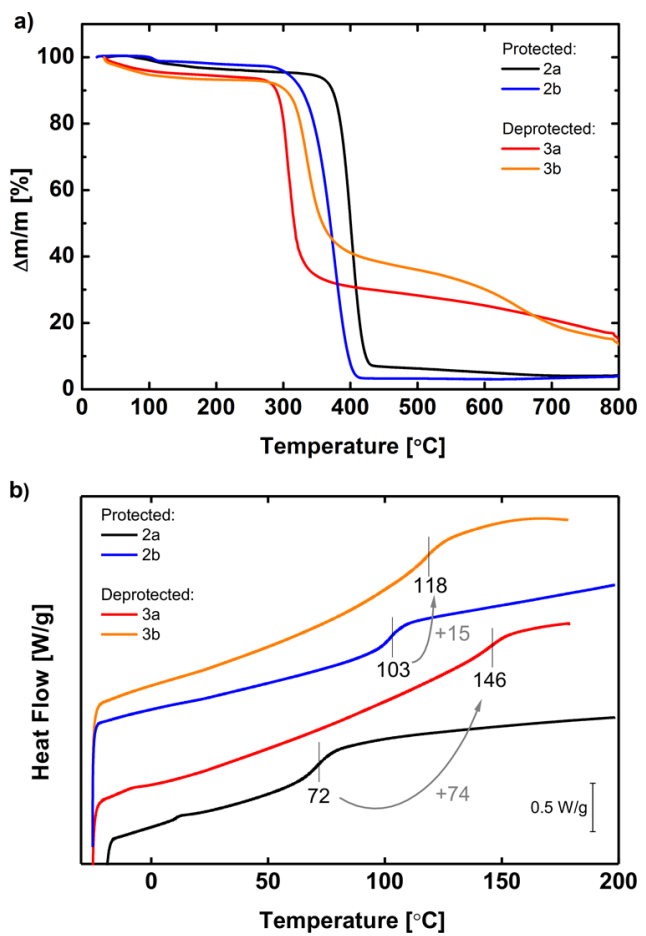

Figure 5. (a) TGA and (b) DSC measurements of protected $\mathbf{2 a}, \mathbf{2} \mathbf{b}$ and deprotected $\mathbf{3 a}, \mathbf{3} \mathbf{b}$ polymers.

degradation temperature: polymer $3 \mathbf{a}$ (6.2\% mass loss until degradation at $\left.252{ }^{\circ} \mathrm{C}\right)$ and polymer $3 \mathbf{b}(7.0 \%$ loss until 253 $\left.{ }^{\circ} \mathrm{C}\right)$. As these polymers are highly hydrophilic due to free $-\mathrm{OH}$ groups, this mass loss is most probably attributed to water de-adsorption. Degradation started at lower temperatures for deprotected polymers $\left(252-253{ }^{\circ} \mathrm{C}\right)$ compared to their protected isomers but the final mass drop until $800{ }^{\circ} \mathrm{C}$ is lower $(85-87 \%)$ compared to protected ones (96\%). The 
lower degradation onset temperature as well as the higher residue at high temperatures is probable because of the presence of the $-\mathrm{OH}$ groups, similar to what was observed in the degradation of bio macromolecules such as lignin.

DSC was measured for protected and deprotected polymers (Figure $5 \mathbf{b}$ ). Protected polymers $\mathbf{2 a}$ and $\mathbf{2} \mathbf{b}$ have lower glass transition $\left(T_{\mathrm{g}}\right)$ temperatures $\left(72-103{ }^{\circ} \mathrm{C}\right)$ compared to ordinary polystyrene $\left(106{ }^{\circ} \mathrm{C}\right)$. Additional -OMe groups may impart some flexibility to the polymer chain thus resulting in these decreased $T_{\mathrm{g}}$ values. ${ }^{31}$ Interestingly, polymer $\mathbf{2 b}$ shows a higher $T_{\mathrm{g}}$ value $\left(103^{\circ} \mathrm{C}\right)$ than $2 \mathrm{a}\left(72^{\circ} \mathrm{C}\right)$, probably due to the restricted mobility. Deprotected polymers $\mathbf{3 a}$ and $\mathbf{3 b}$ contain $-\mathrm{OH}$ groups which can form strong hydrogen bonds. ${ }^{32}$ As a result an increase of $T_{\mathrm{g}}$ is observed in both polymers: $3 \mathrm{a}$ showed a very broad $T_{\mathrm{g}}$ at $146^{\circ} \mathrm{C}$ and $3 \mathrm{~b}$ at 118 ${ }^{\circ} \mathrm{C}$.

Synthesis and Characterization of RPNs. Our main motivation to use cross-linked polymers (RPN) was to study their particle effect on the electrochemistry. Linear polymers are not suitable for this purpose as they are dissolved during synthesis or electrochemical testing. RPNs were prepared by using mini-emulsion polymerization and different amounts of DVB (1-30\% DVB). Both RPN 2a and RPN 2b were successfully synthesized as their FTIR spectra were identical to their linear analogues (Figure S4a,b). In a majority of the experiments, RPN 3a and RPN $3 \mathbf{b}$ only with $1 \%$ DVB were used.

In order to tune the particle size of the RPNs, we varied the amount of surfactant used in the polymerization step at fixed $1 \%$ DVB amount. ${ }^{33}$ Particle sizes of RPN 2a and RPN $\mathbf{2 b}$ were measured using DLS and results are summarized in Table 1. As can be seen, by changing the concentration of the SDS surfactant from 0.09 to $10.0 \mathrm{wt} \%$, the particle size of RPN 2a (Table 1, entries 1-4) varied from 361 to $57 \mathrm{~nm}$ with low PDI $=0.016-0.065$. For preparation of RPN $\mathbf{2} \mathbf{b}$, a high concentration of SDS ( $8 \%$ wt of monomer) was needed to obtain good yield \& low PDI resulting in a particle size $55 \mathrm{~nm}$ by DLS. Attempts to synthesize larger particles of RPN $\mathbf{2 b}$ resulted in agglomeration, high PDI, and low yields and were not used for further experiments. SEM images of RPN 2a and RPN 2b (1\% DVB) were taken to compare particle sizes obtained by DLS (Table 1) and are shown in Figures 6 and 7 . The RPNs display a spherical shape with particle sizes slightly smaller than the ones measured by DLS (0.74-0.84 of DLS). The reason for bigger values is that DLS gives the $z$-average particle diameter while SEM gives a number average particle diameter. Interestingly, the synthesis of very small redox polymer nanoparticles $40 \mathrm{~nm}$ was confirmed by SEM. It may be noted that this value is approaching at the limits of what is possible to produce by conventional mini-emulsion polymerization techniques. $^{34}$

After the deprotection step, the particle size of RPN 3a and RPN 3b (1\% DVB) were also checked by DLS (Table 1) or SEM (Figures 6 and 7). It is worth mentioning, that the extent of the deprotection was confirmed by FTIR by comparison with linear analogues (Figure S4a,b). Furthermore, from the SEM images it is clear that the RPNs keep their spherical shape and in all RPN 3a cases, we could detect particles, indicating that cross-linking with $1 \%$ wt of DVB was enough to prevent dissolution of particles in DCM during the deprotection reaction. In the case of RPN $3 \mathbf{b}$, the DLS data suggest that extensive aggregation occurs and this prevented the analysis of the particles by SEM.

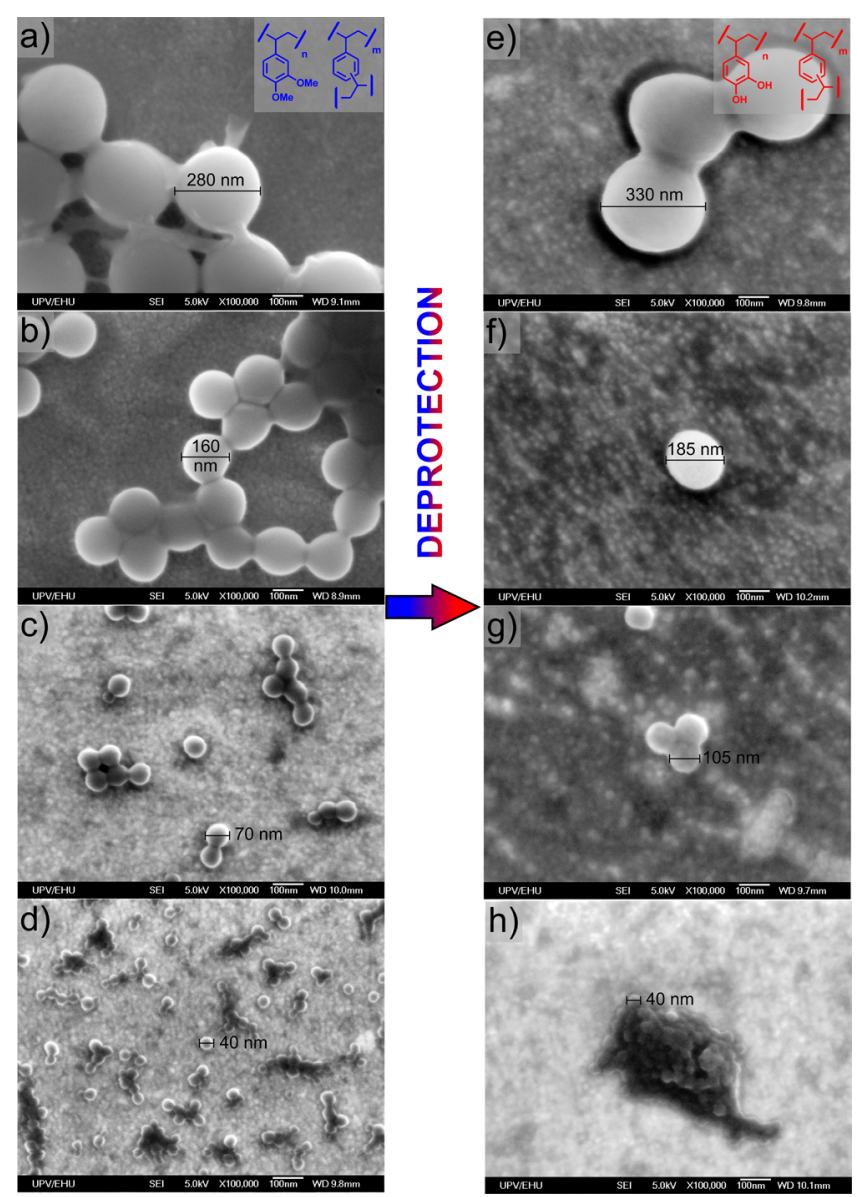

Figure 6. SEM images of $(\mathrm{a}-\mathrm{d})$ protected RPN $2 \mathbf{a}$ and $(\mathrm{e}-\mathrm{h})$ deprotected RPN 3a of different sizes (1\% DVB).

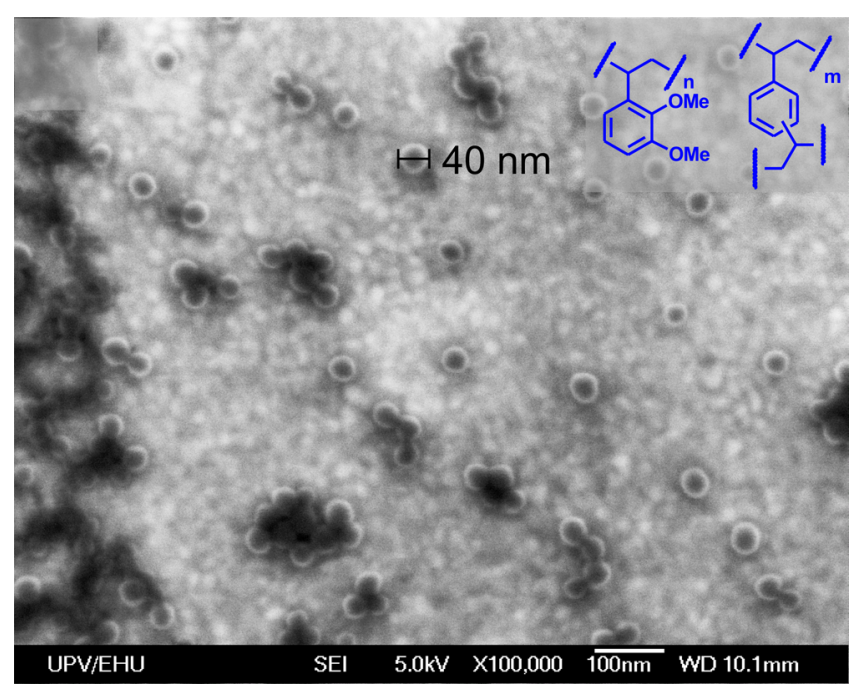

Figure 7. SEM image of protected RPN $\mathbf{2 b}$. Because of extensive aggregation of deprotected RPN $\mathbf{3 b}$ suitable images could not be obtained.

Comparing SEM sizes of RPN 2a with deprotected RPN 3a shows a small increase of $0-50 \%$ of the size for different initial particle sizes (Figure 6). One would expect a huge increase of particle size in aqueous media when we change from hydrophobic RPN 2a and RPN 2 b to hydrophilic RPN 3a and RPN $\mathbf{3 b}$ due to swelling. To prove this hypothesis, particle 

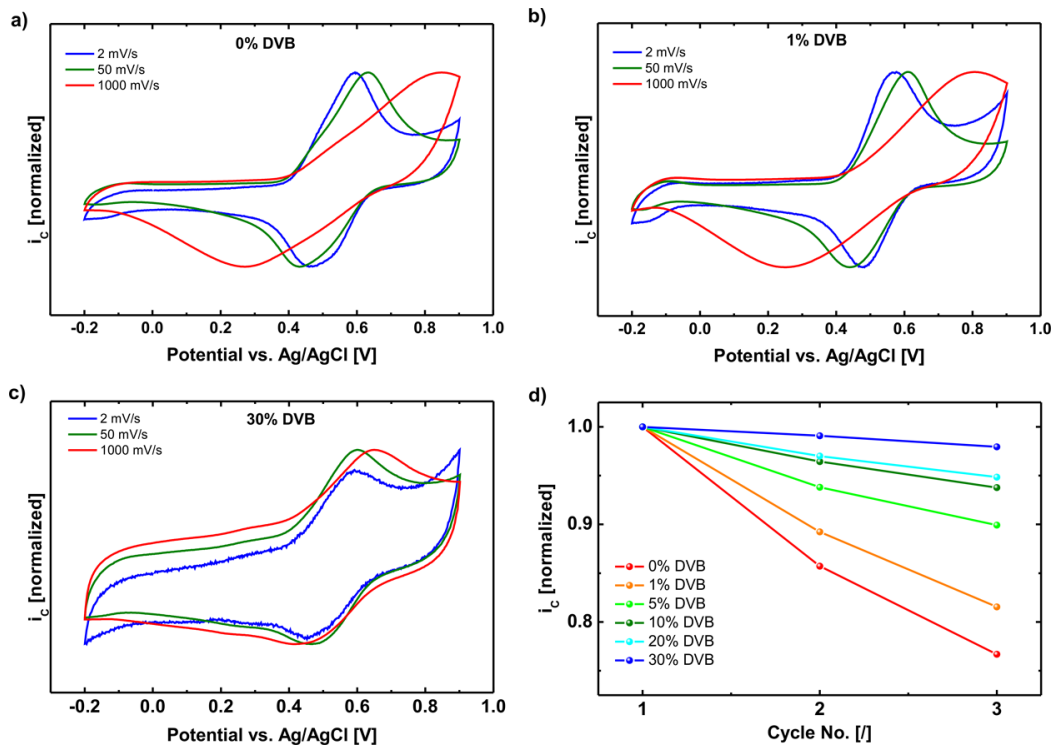

Figure 8. (a) Maximum cathodic current $\left(I_{\mathrm{C}}\right)$ in CV for RPN 3a with different cross-linking ratios of $0-30$ wt $\%$ versus square root of scan rate $(2-1000 \mathrm{mV} / \mathrm{s})$ and (b) cycle stability of RPN 3a with different cross-linking ratios of $0-30$ wt $\%$ at $20 \mathrm{mV} / \mathrm{s}\left(40 \mathrm{~nm}\right.$ particle size, $0.1 \mathrm{M} \mathrm{HClO}{ }_{4}$, -0.2 to $0.9 \mathrm{~V}$ vs $\mathrm{Ag} / \mathrm{AgCl})$.

sizes of RPNs were also measured in water dispersion. A large increase of the particle size after deprotection was observed (Table 1). While this may be due to swelling by water, the increase in PDI values also indicates some particle aggregation. As DLS is a light-scattering technique, it is very sensitive to any aggregation and results for deprotected RPNs in water dispersions must therefore be treated with caution.

Factors That Influence the Electrochemical Performance of RPN. Next, redox polymer nanoparticles were electrochemically tested in three electrode cells using aqueous or nonaqueous electrolytes. First, we investigated the effect of the (i) amount of cross-linker, (ii) electrochemistry of protected versus deprotected RPN, and (iii) size of RPN in the performance of RPN 3a. Then, both RPN 3a and $\mathbf{3 b}$ with the same particle size $40 \mathrm{~nm}$ and 1\% DVB cross-linker were tested in three different electrolytes $\left(0.1 \mathrm{M} \mathrm{HClO}_{4}\right.$ and LiTFSI in water, $0.1 \mathrm{M} \mathrm{LiTFSI}$ in $\mathrm{MeCN}$ ) and compared with each other.

Optimization of Cross-linker Content $40 \mathrm{~nm}$ Particle Size). It was expected that a very low amount of DVB crosslinker could result in poor mechanical stability of nanoparticles and higher tendency to agglomerate together. On the other hand very high DVB content could decrease the swelling of the polymer and inhibit ionic conductivity which would again worsen electrochemical performance. According to this theory, there should be optimal cross-linking content between these two extremes. To prove this RPN 2a were synthesized with 130 wt \% DVB with a similar particle size around $50 \mathrm{~nm}$ (Table 1 , entries 4-8). Then, they were deprotected and resulting RPN 3a (1-30\% DVB) and linear polymer 3a (0\% DVB, no particles) were electrochemically tested in aqueous $0.1 \mathrm{M}$ $\mathrm{HClO}_{4}$ under different sweep rates from 2 to $1000 \mathrm{mV} / \mathrm{s}$ (Figure $8 \mathrm{a}-\mathrm{c}$ ). As expected, the separation of reduction and oxidation peaks increased at higher rates, which is represented in Supporting Information (Figure S5a). At a slow sweep rate of $2 \mathrm{mV} / \mathrm{s}$, the lowest peak separation was $81 \mathrm{mV}$ (1\% DVB) and the largest $119 \mathrm{mV}(0 \% \mathrm{DVB})$. At a fast sweep rate of $1000 \mathrm{mV} / \mathrm{s}$, the lowest peak separation was $186 \mathrm{mV}(30 \%$ DVB) and the largest was $496 \mathrm{mV}$ (0\% DVB). Coulombic efficiency was also tested for three selected RPN 3a (0, 1, and $30 \%$ DVB). Because of similar results, we can conclude the cross-linking ratio does not have big influence on the Coulombic efficiency (Figure S5b). At $2 \mathrm{mV} / \mathrm{s}$, it was around $75-75 \%$ and increased to $96-98 \%$ at $1000 \mathrm{mV} / \mathrm{s}$ which is common behavior because of fewer side reactions at fast scan rates. The maximum cathodic current $\left(I_{\mathrm{C}}\right)$ was also measured for different cross-linking ratios $(0-30 \%$ DVB) at different scan rates $(2-1000 \mathrm{mV} / \mathrm{s})$. The highest electroactivity with $I_{\mathrm{C}}$ $=2274 \mu \mathrm{A}$ was observed with $0 \% \mathrm{DVB}$ at $1000 \mathrm{mV} / \mathrm{s}$ (Figure $\mathrm{S} 6 \mathrm{a})$. Higher amounts of DVB resulted in decreased activities $I_{\mathrm{C}}=850 \mu \mathrm{A}(5$ and $10 \% \mathrm{DVB})$ and $270 \mu \mathrm{A}(20$ and $30 \%$ DVB). To check if the reaction is diffusion- or surfacecontrolled, $I_{C}$ was plotted against square root of scan rate (Figure S6a,b) and against scan rate (Figure S6c-e). As there was no linear correlation, we can conclude that the reaction is not diffusion- neither surface-controlled.

Another motivation to use cross-linked RPN was also to stabilize the capacity. It is known from the literature that a main drawback of Li-organic batteries is capacity fading and self-discharge. The main reason is dissolution of organic compounds in the battery electrolyte and could be solved by the use of insoluble cross-linked polymers such as our RPNs. To test our hypothesis, the maximum cathodic current $\left(I_{\mathrm{C}}\right)$ of RPN 3a with different cross-linking ratios 0-30\% DVB was plotted versus cycle number (Figure $8 \mathrm{~d}$ ). What we can observe is a clear improvement of cycle stability from 76.7 to $97.9 \%$ in 3 cycles when we move from 0 to $30 \%$ DVB. These are only short term cyclability experiments and more tests needs to be done in the future but they show a clear trend that crosslinking improves cycling stability.

To check morphology of RPN with different DVB contents, SEM was also performed (Figure S7). From the SEM images, it is evident that particles with low DVB content tend to fuse together but $10 \mathrm{wt} \%$ of DVB is already enough to get separated particles. From electrochemistry, it is evident that fusing of the particles does not negatively affect electrochemical performance. The main factor seems to be the high 
swelling of the RPNs at low cross-linker contents which promotes ionic conductivity and increases electroactivity.

Redox Activity of Protected Versus Deprotected RPN (1\% $D V B, 40 \mathrm{~nm}$ Size). Redox active polymer nanoparticles based on poly(4-vinyl catechol) RPN 3a were tested in the aqueous $0.1 \mathrm{M} \mathrm{HClO}_{4}$ electrolyte and compared to its protected precursor RPN 2a. As expected RPN 3a shows a very nice reversible peak at $0.45 \mathrm{~V} / 0.60 \mathrm{~V}$ versus $\mathrm{Ag} / \mathrm{AgCl}$ for reduction and oxidation of catechol, respectively (Figure 9a). On the
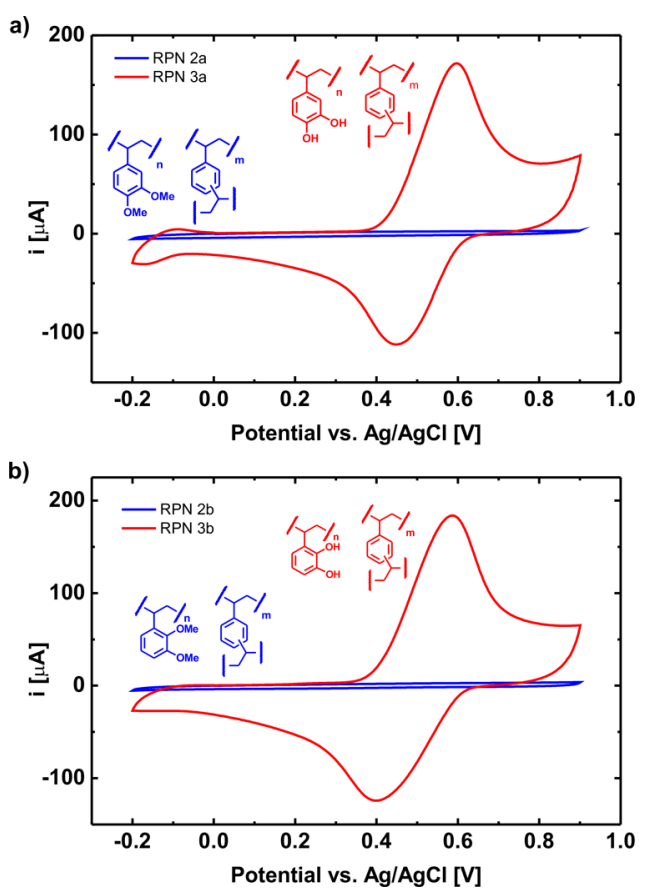

Figure 9. Cyclic voltammograms (CV) of: (a) protected RPN $2 a$ and deprotected RPN 3a and (b) RPN $2 b$ and $3 b(1 \%$ DVB, $40 \mathrm{~nm}$ particle size, 3 rd cycle, $20 \mathrm{mV} / \mathrm{s}, 0.1 \mathrm{M} \mathrm{HClO}_{4}$ electrolyte, $-0.2-0.9$ $\mathrm{V}$ vs $\mathrm{Ag} / \mathrm{AgCl}$ ).

other hand, it is protected precursors RPN 2a shows no redox activity. Similar results were obtained with another RPN $\mathbf{3 b}$ (1\% DVB) which confirms the need of the chemical deprotection step (Figure 9b).

We also wanted to check if deprotection could be performed by electrochemical oxidation to avoid the chemical deprotection step. In aqueous $0.1 \mathrm{M} \mathrm{HClO}_{4}$, both RPN $2 \mathrm{a}$ and RPN $2 \mathrm{~b}$ were cycled using a full stability window of electrolyte -0.5-1.8 V versus $\mathrm{Ag} / \mathrm{AgCl}$ (Figure S8a,b). Only an irreversible peak above $1.0 \mathrm{~V}$ versus $\mathrm{Ag} / \mathrm{AgCl}$ was noticed which disappeared after few cycles, but no reversible quinone peaks were observed. From these results, we can conclude that electrochemical deprotection is not possible under these conditions.

Particle Size Effect (1\% DVB). For checking the effect of the particle size into the electrochemical performance, RPN 3a with different SEM sizes 330, 185, 105, and $40 \mathrm{~nm}$ (Table 1, entries 1-4) were tested in aqueous $0.1 \mathrm{M} \mathrm{HClO}_{4}$ (Figure 10). The CV showed almost no difference at our standard sweep rate $20 \mathrm{mV} / \mathrm{s}$, so we performed an experiment at a much faster rate of $1000 \mathrm{mV} / \mathrm{s}$. Only the biggest particles $330 \mathrm{~nm}$ have showed lower electrochemical activity. Smaller particles from 185 to $40 \mathrm{~nm}$ do not show any significant difference. For

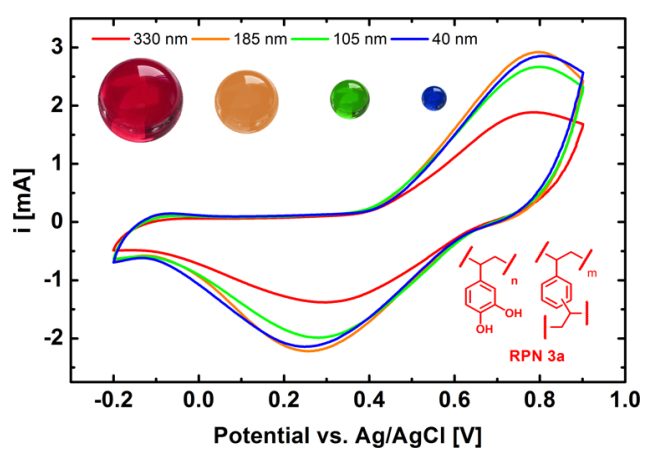

Figure 10. CV of RPN 3a (1\% DVB) with different particle sizes at a scan rate $1000 \mathrm{mV} / \mathrm{s}$.

further electrochemical tests of RPN $3 a$ and RPN $3 b$, we decided to use only the smallest particle size $40 \mathrm{~nm}$.

Testing Different Electrolytes. In this section, the chemical nature of the polymer and its redox behavior in different electrolytes were investigated in detail. Three different electrolytes were investigated and compared among them with two RPN 3a and RPN 3b with $40 \mathrm{~nm}$ particle size and $1 \%$ DVB cross-linker.

Acidic Aqueous Electrolyte (1\% DVB, $40 \mathrm{~nm}$ Particle Size). $\mathrm{RPN} 3 \mathrm{a}$ showed a very nice reversible peak at $0.45 / 0.60 \mathrm{~V}$ versus $\mathrm{Ag} / \mathrm{AgCl}$ for reduction and oxidation, respectively (Figure 11a). The proposed redox reaction is the oxidation of
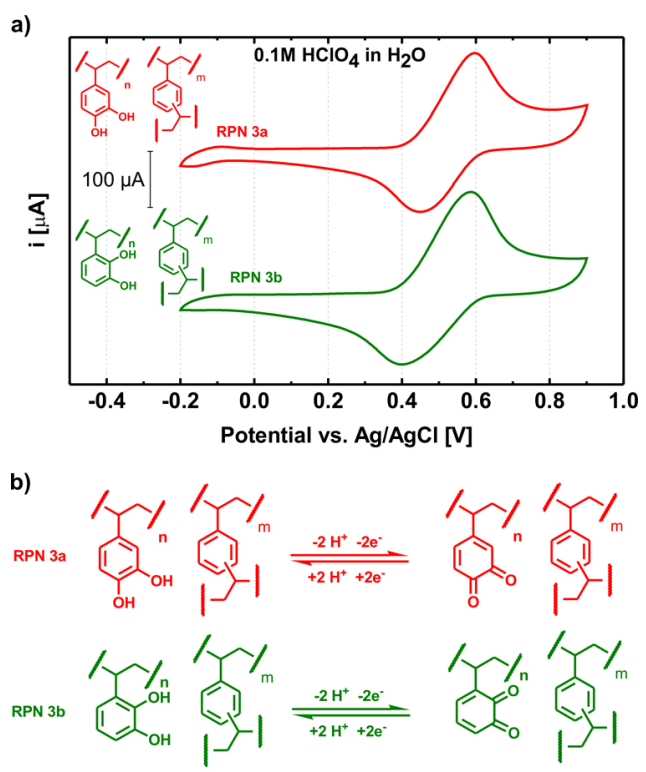

Figure 11. (a) CV comparison of RPN $3 a$ and RPN $3 b$ in $0.1 \mathrm{M}$ $\mathrm{HClO}_{4}$ electrolyte ( $1 \% \mathrm{DVB}, 40 \mathrm{~nm}$ particle size, $3^{\text {rd }}$ cycle, $20 \mathrm{mV} / \mathrm{s}$, $-0.2-0.9 \mathrm{~V}$ vs $\mathrm{Ag} / \mathrm{AgCl}$ ). (b) Schematic representation of proposed redox reaction of RPNs in acidic aqueous electrolyte.

catechol group into o-benzoquinone (Figure 11b). Similar results were obtained with RPN $3 \mathrm{~b}$ with slightly lower values $0.40 / 0.59 \mathrm{~V}$ versus $\mathrm{Ag} / \mathrm{AgCl}$. This small decrease in reduction potential can be due to a slightly different structure: RPN 3a is poly(4-vinylcatechol) and RPN $3 b$ is poly(3-vinylcatechol). One potential reason for this observation is the improved stabilization of two neighboring catechols by hydrogen bonds for the RPN $3 b$ isomer.

Our electrochemical results are also compared with the literature (Table 2). Reduction potentials are in the region 
Table 2. Redox Potentials for Different Poly(catechol)s from the Literature

\begin{tabular}{|c|c|c|c|c|c|}
\hline Compound & RPN $3 \mathrm{a}$ & $\begin{array}{l}\text { TFSI } \\
\text { PVIm-cat- } \\
\text { TFS }\end{array}$ & $\begin{array}{l}\mathrm{OH} \\
\mathrm{P}(\mathrm{DA}){ }_{100}\end{array}$ & $\begin{array}{l}\mathrm{HO} \\
\mathrm{P}(\mathrm{VIm}-\mathrm{OH} \text { cat- } \\
\mathrm{Cl})_{100}\end{array}$ & $\mathrm{P}(4 \mathrm{VC})_{100}$ \\
\hline Electrolyte & $\begin{array}{c}0.1 \mathrm{M} \mathrm{HClO}_{4} \\
(\mathrm{pH}=1.0)\end{array}$ & $\begin{array}{c}0.1 \mathrm{M} \text { acetate } \\
\text { buffer } \\
(\mathrm{pH}=3.5)\end{array}$ & $\begin{array}{c}1 \mathrm{M} \mathrm{H}_{2} \mathrm{SO}_{4} \\
(\mathrm{pH}=0)\end{array}$ & $\begin{array}{c}1 \mathrm{M} \mathrm{H}_{2} \mathrm{SO}_{4} \\
(\mathrm{pH}=0) \mathrm{v}\end{array}$ & $\begin{array}{c}1 \mathrm{M} \mathrm{H}_{2} \mathrm{SO}_{4} \\
(\mathrm{pH}=0)\end{array}$ \\
\hline $\begin{array}{l}\text { Reduction potential } \\
\text { [V vs. } \mathrm{Ag} / \mathrm{AgCl}]\end{array}$ & $0.45 \mathrm{~V}$ & $0.32 \mathrm{~V}$ & $0.525 \mathrm{~V}$ & $0.63 \mathrm{~V}$ & $0.525 \mathrm{~V}$ \\
\hline Reference & This article & 18 & 22 & 22 & 22 \\
\hline
\end{tabular}

0.32-0.63 V versus $\mathrm{Ag} / \mathrm{AgCl}$ and differences can be mainly attributed to different $\mathrm{pH}=0-3.5$, different electrolytes and polymer structures. It can be generally observed that more acidic media (low $\mathrm{pH}$ ) resulted in higher reduction potentials.

Neutral Aqueous Electrolyte Containing LiTFSI Salt (1\% $D V B, 40 \mathrm{~nm}$ Particle Size). It was shown in the literature that catechols have reversible electrochemistry in acidic aqueous electrolytes but under neutral conditions they can irreversibly polymerize or react with nucleophiles. ${ }^{35}$ To check if our RPNs work also in neutral conditions, they were tested in aqueous $0.1 \mathrm{M}$ LiTFSI. RPN 3a shows interesting behavior as CV changes with cycles (Figure S9a). The first oxidation peak at $0.54 \mathrm{~V}$ disappears in three cycles. At lower voltages, we can see a nice reversible reduction/oxidation peak at $0.01 / 0.12 \mathrm{~V}$ versus $\mathrm{Ag} / \mathrm{AgCl}$. If we cycle only until $0.30 \mathrm{~V}$, only very poor electroactivity can be obtained (Figure S9a, inset). It seems that going to higher voltages until $0.90 \mathrm{~V}$ is crucial if we want to obtain a reversible redox pair at lower voltages (activation step). Similar behavior with the activation step was also noticed with RPN 3b (Figure S9b, inset). It was initially thought that this was a result of irreversible polymerization/ reaction with nucleophile. ${ }^{35}$ However, further tests revealed that after switching back from neutral to acidic $\mathrm{HClO}_{4}$ electrolyte, the initial reversible redox peaks at $0.4 / 0.59 \mathrm{~V}$ versus $\mathrm{Ag} / \mathrm{AgCl}$ were completely restored in the case of RPN $3 \mathrm{~b}$ as an example (Figure 12). Because of these results, we concluded that there is no irreversible reaction in neutral $0.1 \mathrm{M}$ LiTFSI electrolyte but reversible change of the redox pair from hydroquinone/quinone to hydroquinone lithium salt/quinone (reaction schemes in Figure 12), which has a lower voltage because of the negative charge on oxygen and is a known phenomenon from the literature. ${ }^{1,36-42}$ Compared to $0.1 \mathrm{M}$ $\mathrm{HClO}_{4}$, reduction peak in $0.1 \mathrm{M}$ LiTFSI is shifted $440 \mathrm{mV}$ for $\mathrm{RPN} 3 \mathrm{a}$ and $475 \mathrm{mV}$ for RPN $3 \mathrm{~b}$ to lower potential.

Organic Electrolyte Based on LiTFSI in Acetonitrile (1\% $D V B, 40 \mathrm{~nm}$ Particle Size). To test if the synthesized polymer nanoparticles also work in organic electrolytes, all three polymers were tested in $0.1 \mathrm{M}$ LiTFSI in anhydrous acetonitrile $(\mathrm{MeCN})$. A nonaqueous reference electrode was used based on $\mathrm{Ag} / \mathrm{Ag}^{+}$in $\mathrm{MeCN}$ (see experimental part). In the case of RPN 3a, a huge oxidation (activation) peak was observed at $1.22 \mathrm{~V}$ versus $\mathrm{Ag} / \mathrm{Ag}^{+}$which disappeared completely after the first cycle (Figure S10a). Reversible reduction/oxidation was observed at $-0.24 / 0.01 \mathrm{~V}$ versus $\mathrm{Ag} /$ $\mathrm{Ag}^{+}$. Again, as in the case of aqueous electrolyte, a first activation cycle is necessary to obtain good electrochemical performance (Figure S10a, inset). RPN $3 \mathrm{~b}$ has two activation peaks at 0.91 and $1.20 \mathrm{~V}$ versus $\mathrm{Ag} / \mathrm{Ag}^{+}$(Figure $\mathrm{S} 10 \mathrm{~b}$ ) during the first cycle followed by two reduction/two oxidation peaks

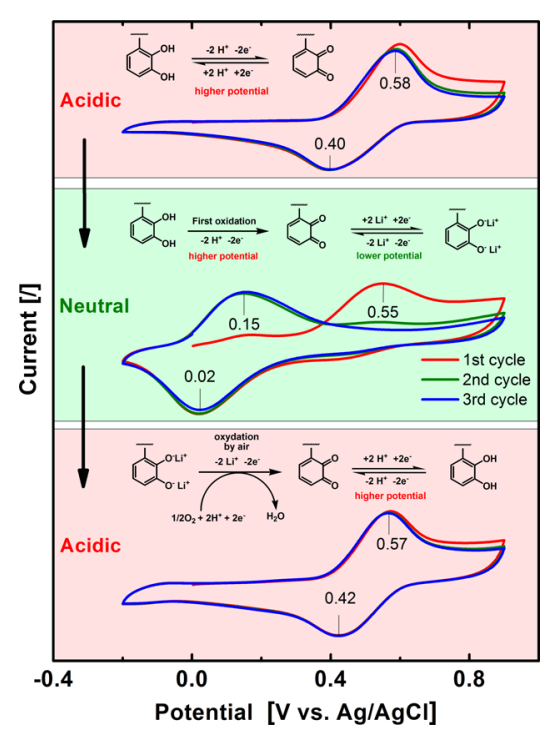

Figure 12. CV of RPN $3 \mathrm{~b}$ when moved from $0.1 \mathrm{M} \mathrm{HClO}_{4}$ to $1 \mathrm{M}$ $\mathrm{Na}_{2} \mathrm{SO}_{4}$ and then back to $\mathrm{HClO}_{4}$ electrolyte $(1 \% \mathrm{DVB}, 40 \mathrm{~nm}$ particle size, $20 \mathrm{mV} / \mathrm{s},-0.2-0.9 \mathrm{~V}$ vs $\mathrm{Ag} / \mathrm{AgCl})$.

at $0.32,-0.24 / 0.15,0.69 \mathrm{~V}$ versus $\mathrm{Ag} / \mathrm{Ag}^{+}$. This is in contrast to the aqueous electrolyte, where only one peak is observed. Electrochemical results of poly(catechols) in organic electrolytes cannot be easily compared with the literature ${ }^{19,21}$ due to differences in electrolytes, references, and so forth.

Comparison of electrochemical results of both RPNs (1\% DVB, $40 \mathrm{~nm}$ particle size) in all three electrolytes is presented in Figures $11 \mathrm{a}$ and $13 \mathrm{a}$,b. When $0.1 \mathrm{M} \mathrm{HClO}_{4}$ was replaced with $0.1 \mathrm{M}$ LiTFSI salt, lower potentials were observed due to the formation of lithium salts. The main reason why we tested two isomers is to check which one has better electrochemical properties. As expected, both have very similar redox potentials in $0.1 \mathrm{M} \mathrm{HClO}_{4}$ as they both contain the catechol redox group. They also have the same theoretical capacity $(394 \mathrm{~mA} \mathrm{~h} / \mathrm{g})$. However, in terms of other properties they can be quite different: different polymer structures and stacking of polymer chains can influence swelling in different electrolytes and other properties. Swelling has a great impact on electrochemical performance, ionic conductivity, and utilization of redox material. RPN 3b performed best in aqueous $0.1 \mathrm{M} \mathrm{HClO}_{4}$ electrolyte but contrary to RPN $3 a$ in $0.1 \mathrm{M}$ LiTFSI in the $\mathrm{MeCN}$ electrolyte. In the MeCN electrolyte, RPN 3a had one big reduction/oxidation peak but RPN $3 b$ had two small oxidation/reduction peaks. These differences in redox behavior are thought to be because of differences in the stability of the intermediate radical anions. In the case of RPN $3 b$, the 


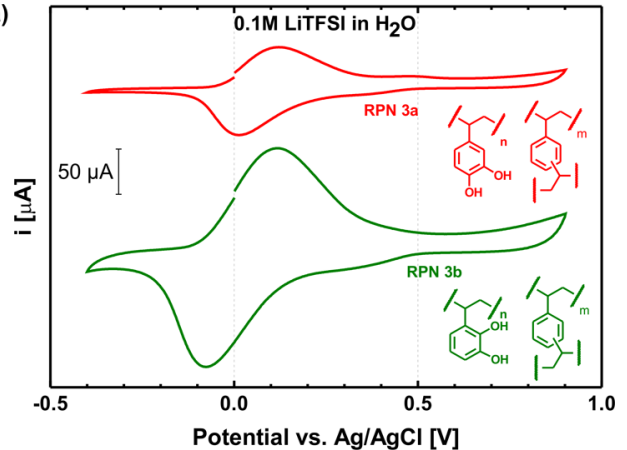

b)

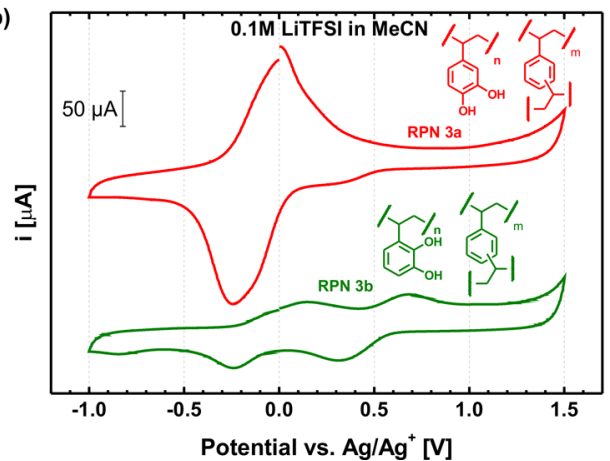

Figure 13. (a) CV of RPNs $3 a$ and RPN $3 b$ in aqueous and (b) MeCN electrolyte. (1\% DVB, $40 \mathrm{~nm}$ particle size, 3rd cycle, $0.1 \mathrm{M}$ LiTFSI salt, $20 \mathrm{mV} / \mathrm{s}$, potential vs $\mathrm{Ag} / \mathrm{AgCl}$ or $\mathrm{Ag} / \mathrm{Ag}^{+}$).

intermediate radical anion is relatively stable on the timeframe of the $\mathrm{CV}$ in the acetonitrile-based electrolyte, and therefore, the second electron redox reaction follows after the first oneas a result two peaks are visible in $\mathrm{CV}$. On the other hand, the intermediate $\mathrm{RPN} 3 \mathrm{a}^{-\bullet}$ radical anion seems to be less stable and the second electron reaction proceeds concurrently with the first one. Thus, for RPN 3a only one peak in the CV is observed. It should, however, be noted that the appearance of one or two peaks depends on the conditions used during the CV experiment. Similar behavior was already shown with anthraquinone, where one or two reduction/oxidation peaks could be visible depending on the solvent, salt, electrode composition, scan rate, and so forth. ${ }^{43,44}$

\section{CONCLUSIONS}

In this article, the first example of the synthesis of redox active polymer nanoparticles (RPN) based on poly(vinyl catechol) is presented. A two-step process was developed involving a miniemulsion polymerization step and a deprotection step to generate the RPNs. RPNs based on two different poly(vinyl catechol)s were prepared: poly(4-vinyl catechol) (3a) and poly(3-vinyl catechol) (3b). By changing the concentration of the surfactant during polymerization, we were able to prepare spherical polymer nanoparticles with different particle sizes ranging from $360-40 \mathrm{~nm}$. Both polymers showed slightly different but similar trends in their glass transition temperatures and degradation temperatures. To the best of our knowledge, this method produces the smallest redox active polymer nanoparticles reported so far $(40 \mathrm{~nm})$. The electrochemical properties of the RPN were tested in aqueous and acetonitrile-based electrolytes using CV. The effect of the nanoparticle size and the cross-linker content in the electrochemical properties was first investigated and small particles $(\approx 40 \mathrm{~nm})$ with low $(1 \%)$ cross-linker content showed the highest electroactivity. Both RPNs showed reversible behavior in aqueous acidic-, neutral-, as well as in acetonitrile-based electrolyte. In acidic aqueous media, similar results were observed for poly(4-vinyl catechol) (RPN 3a) and poly(3-vinyl catechol) (RPN 3b) with a reversible redox process taking place at 0.45 and $0.40 \mathrm{~V}$ versus $\mathrm{Ag} / \mathrm{AgCl}$, respectively (for reduction). When switching from the acidic aqueous electrolyte to neutral, the redox potential was shifted $440-475 \mathrm{mV}$ to lower values. However, in the case of acetonitrile-based electrolyte, the two isomers showed different behavior, and in the case of the poly(3-vinyl catechol) (RPN 3b) two redox processes are observed. On the basis of the electrochemical potentials, RPN 3a seems to be more attractive to be used in organic batteries. However, as in this study the specific capacity could not be measured exactly and future work will be required in order to determine the efficiency of such RPNs as cathodes in organic batteries.

\section{ASSOCIATED CONTENT}

\section{Supporting Information}

The Supporting Information is available free of charge on the ACS Publications website at DOI: 10.1021/acs.macromol.9b01405.

Monomer synthesis, polymerization in dispersed media, deprotection reaction, apparatures used, preparation of electrodes, and electrochemical three-electrode setup, and additional characterization: NMR, FTIR, DLS, SEM images, and CV (PDF)

\section{AUTHOR INFORMATION}

\section{Corresponding Author}

*E-mail: klemen.pirnat@ki.si.

ORCID $\odot$

Klemen Pirnat: 0000-0003-0953-4108

David Mecerreyes: 0000-0002-0788-7156

Notes

The authors declare no competing financial interest.

\section{ACKNOWLEDGMENTS}

This work was financially supported by the European Research Council by Starting Grant Innovative Polymers for Energy Storage (iPes) 30625 and Slovenian research agency (ARRS): research project J2-8167 and public call MS-ERC-FS/2017002. N.B. acknowledges the financial support obtained through the Post-Doctoral fellowship Juan de la Cierva-Incorporación (IJCI-2016-28442), from the Ministry of Economy and Competitiveness of Spain. L.P. has received funding from the European Union's Horizon 2020 research and innovation programme under the Marie Skłodowska-Curie grant agreement no 797295 .

\section{REFERENCES}

(1) Chen, H.; Armand, M.; Demailly, G.; Dolhem, F.; Poizot, P.; Tarascon, J.-M. From Biomass to a Renewable LiXC6O6 Organic Electrode for Sustainable Li-Ion Batteries. ChemSusChem 2008, 1, 348-355.

(2) Zhao, Q.; Lu, Y.; Chen, J. Advanced Organic Electrode Materials for Rechargeable Sodium-Ion Batteries. Adv. Energy Mater. 2017, 7, 1601792 .

(3) Liang, Y.; Tao, Z.; Chen, J. Organic Electrode Materials for Rechargeable Lithium Batteries. Adv. Energy Mater. 2012, 2, 742-769. 
(4) Song, Z.; Zhou, H. Towards Sustainable and Versatile Energy Storage Devices: An Overview of Organic Electrode Materials. Energy Environ. Sci. 2013, 6, 2280-2301.

(5) Muench, S.; Wild, A.; Friebe, C.; Häupler, B.; Janoschka, T.; Schubert, U. S. Polymer-Based Organic Batteries. Chem. Rev. 2016, 116, 9438-9484.

(6) Schon, T. B.; McAllister, B. T.; Li, P.-F.; Seferos, D. S. The Rise of Organic Electrode Materials for Energy Storage. Chem. Soc. Rev. 2016, 45, 6345-6404.

(7) Montoto, E. C.; Nagarjuna, G.; Hui, J.; Burgess, M.; Sekerak, N. M.; Hernández-Burgos, K.; Wei, T.-S.; Kneer, M.; Grolman, J.; Cheng, K. J.; et al. Redox Active Colloids as Discrete Energy Storage Carriers. J. Am. Chem. Soc. 2016, 138, 13230-13237.

(8) Jugović, D.; Uskoković, D. A Review of Recent Developments in the Synthesis Procedures of Lithium Iron Phosphate Powders. J. Power Sources 2009, 190, 538-544.

(9) Hatakeyama-Sato, K.; Nagano, T.; Noguchi, S.; Sugai, Y.; Du, J.; Nishide, H.; Oyaizu, K. Hydrophilic Organic Redox-Active Polymer Nanoparticles for Higher Energy Density Flow Batteries. ACS Appl. Polym. Mater. 2019, 1, 188-196.

(10) Casado, N.; Hernández, G.; Sardon, H.; Mecerreyes, D. Current Trends in Redox Polymers for Energy and Medicine. Prog. Polym. Sci. 2016, 52, 107-135.

(11) Zhuo, S.; Tang, M.; Wu, Y.; Chen, Y.; Zhu, S.; Wang, Q.; Xia, C.; Wang, C. Size Control of Zwitterionic Polymer Micro/ Nanospheres and Its Dependence on Sodium Storage. Nanoscale Horiz. 2019, 4, 1092-1098.

(12) Janoschka, T.; Hager, M. D.; Schubert, U. S. Powering up the Future: Radical Polymers for Battery Applications. Adv. Mater. 2012, 24, 6397-6409.

(13) Häupler, B.; Wild, A.; Schubert, U. S. Carbonyls: Powerful Organic Materials for Secondary Batteries. Adv. Energy Mater. 2015, 5, 1402034.

(14) Bhosale, M. E.; Chae, S.; Kim, J. M.; Choi, J.-Y. Organic Small Molecules and Polymers as an Electrode Material for Rechargeable Lithium Ion Batteries. J. Mater. Chem. A 2018, 6, 19885-19911.

(15) Novák, P.; Müller, K.; Santhanam, K. S. V.; Haas, O. Electrochemically Active Polymers for Rechargeable Batteries. Chem. Rev. 1997, 97, 207-282.

(16) Conant, J. B.; Fieser, L. F. Reduction Potentials of Quinones. II. The Potentials of Certain Derivatives of Benzoquinone, Naphthoquinone and Anthraquinone. J. Am. Chem. Soc. 1924, 46, 1858-1881.

(17) Zhu, X.-Q.; Wang, C.-H. Accurate Estimation of the OneElectron Reduction Potentials of Various Substituted Quinones in DMSO and CH3CN. J. Org. Chem. 2010, 75, 5037-5047.

(18) Patil, N.; Cordella, D.; Aqil, A.; Debuigne, A.; Admassie, S.; Jérôme, C.; Detrembleur, C. Surface- and Redox-Active Multifunctional Polyphenol-Derived Poly(Ionic Liquid)s: Controlled Synthesis and Characterization. Macromolecules 2016, 49, 7676-7691.

(19) Patil, N.; Aqil, A.; Ouhib, F.; Admassie, S.; Inganäs, O.; Jérôme, C.; Detrembleur, C. Bioinspired Redox-Active Catechol-Bearing Polymers as Ultrarobust Organic Cathodes for Lithium Storage. Adv. Mater. 2017, 29, 1703373.

(20) Patil, N.; Jérôme, C.; Detrembleur, C. Recent Advances in the Synthesis of Catechol-Derived (Bio)Polymers for Applications in Energy Storage and Environment. Prog. Polym. Sci. 2018, 82, 34-91.

(21) Patil, N.; Aqil, M.; Aqil, A.; Ouhib, F.; Marcilla, R.; Minoia, A.; Lazzaroni, R.; Jérôme, C.; Detrembleur, C. Integration of RedoxActive Catechol Pendants into Poly(Ionic Liquid) for the Design of High-Performance Lithium-Ion Battery Cathodes. Chem. Mater. 2018, $30,5831-5835$.

(22) Patil, N.; Mavrandonakis, A.; Jérôme, C.; Detrembleur, C.; Palma, J.; Marcilla, R. Polymers Bearing Catechol Pendants as Universal Hosts for Aqueous Rechargeable $\mathrm{H}+$, Li-Ion, and Post-Liion (Mono-, Di-, and Trivalent) Batteries. ACS Appl. Energy Mater. 2019, 2, 3035-3041.

(23) Vizintin, A.; Bitenc, J.; Kopač Lautar, A.; Pirnat, K.; Grdadolnik, J.; Stare, J.; Randon-Vitanova, A.; Dominko, R. Probing Electro- chemical Reactions in Organic Cathode Materials via in Operando Infrared Spectroscopy. Nat. Commun. 2018, 9, 661.

(24) Takeshima, H.; Satoh, K.; Kamigaito, M. Bio-Based Functional Styrene Monomers Derived from Naturally Occurring Ferulic Acid for Poly(Vinylcatechol) and Poly(Vinylguaiacol) via Controlled Radical Polymerization. Macromolecules 2017, 50, 4206-4216.

(25) Kucerovy, A.; Li, T.; Prasad, K.; Repic, O.; Blacklock, T. J.; Repič, O.; Blacklock, T. J. An Efficient Large-Scale Synthesis of Methyl 5-[2-(2,5-Dimethoxyphenyl)Ethyl]-2-Hydroxybenzoate. Org. Process Res. Dev. 1997, 1, 287-293.

(26) Gottlieb, H. E.; Kotlyar, V.; Nudelman, A. NMR Chemical Shifts of Common Laboratory Solvents as Trace Impurities. J. Org. Chem. 1997, 62, 7512-7515.

(27) Metz, G.; Wu, X. L.; Smith, S. O. Ramped-Amplitude Cross Polarization in Magic-Angle-Spinning NMR. J. Magn. Reson., Ser. A 1994, 110, 219-227.

(28) Detken, A.; Hardy, E. H.; Ernst, M.; Meier, B. H. Simple and Efficient Decoupling in Magic-Angle Spinning Solid-State NMR: The XiX Scheme. Chem. Phys. Lett. 2002, 356, 298-304.

(29) Xue, J.; Zhang, Z.; Nie, J.; Du, B. Formation of Microgels by Utilizing the Reactivity of Catechols with Radicals. Macromolecules 2017, 50, 5285-5292.

(30) Stevens, M. P. Polymer Chemistry an Introduction, 3rd ed.; Oxford University Press: New York, 1999.

(31) Matos-Pérez, C. R.; White, J. D.; Wilker, J. J. Polymer Composition and Substrate Influences on the Adhesive Bonding of a Biomimetic, Cross-Linking Polymer. J. Am. Chem. Soc. 2012, 134, 9498-9505.

(32) Nakamura, K.; Hatakeyama, T.; Hatakeyama, H. DSC Studies on Hydrogen Bonding of Poly(4-Hydroxy-3,5-Dimethoxystyrene) and Related Derivatives. Polym. J. 1986, 18, 219-225.

(33) Miller, C. M.; Sudol, E. D.; Silebi, C. A.; El-Aasser, M. S. Miniemulsion Polymerization of Styrene: Evolution of the Particle Size Distribution. J. Polym. Sci., Part A: Polym. Chem. 1995, 33, 13911408.

(34) Anderson, C. D.; Sudol, E. D.; El-Aasser, M. S. $50 \mathrm{Nm}$ Polystyrene Particles Via Miniemulsion Polymerization. Macromolecules 2002, 35, 574-576.

(35) Kiani, A.; Raoof, J.-B.; Nematollahi, D.; Ojani, R. Electrochemical Study of Catechol in the Presence of Dibuthylamine and Diethylamine in Aqueous Media: Part 1. Electrochemical Investigation. Electroanalysis 2005, 17, 1755-1760.

(36) Xiang, J.; Chang, C.; Li, M.; Wu, S.; Yuan, L.; Sun, J. A Novel Coordination Polymer as Positive Electrode Material for Lithium Ion Battery. Cryst. Growth Des. 2008, 8, 280-282.

(37) Chen, H.; Poizot, P.; Dolhem, F.; Basir, N. I.; Mentré, O.; Tarascon, J.-M. Electrochemical Reactivity of Lithium Chloranilate vs $\mathrm{Li}$ and Crystal Structures of the Hydrated Phases. Electrochem. SolidState Lett. 2009, 12, A102-A106.

(38) Zeng, R.-h.; Li, X.-p.; Qiu, Y.-c.; Li, W.-s.; Yi, J.; Lu, D.-s.; Tan, C.-1.; Xu, M.-q. Synthesis and Properties of a Lithium-Organic Coordination Compound as Lithium-Inserted Material for Lithium Ion Batteries. Electrochem. Commun. 2010, 12, 1253-1256.

(39) Yao, M.; Araki, M.; Senoh, H.; Yamazaki, S.-i.; Sakai, T.; Yasuda, K. Indigo Dye as a Positive-Electrode Material for Rechargeable Lithium Batteries. Chem. Lett. 2010, 39, 950-952.

(40) Renault, S.; Geng, J.; Dolhem, F.; Poizot, P. Evaluation of Polyketones with N-Cyclic Structure as Electrode Material for Electrochemical Energy Storage: Case of Pyromellitic Diimide Dilithium Salt. Chem. Commun. 2011, 47, 2414-2416.

(41) Barrès, A.-L.; Geng, J.; Bonnard, G.; Renault, S.; Gottis, S.; Mentré, O.; Frayret, C.; Dolhem, F.; Poizot, P. High-Potential Reversible Li Deintercalation in a Substituted Tetrahydroxy-pBenzoquinone Dilithium Salt: An Experimental and Theoretical Study. Chem.-Eur. J. 2012, 18, 8800-8812.

(42) Renault, S.; Gottis, S.; Barrès, A.-L.; Courty, M.; Chauvet, O.; Dolhem, F.; Poizot, P. A green Li-organic battery working as a fuel cell in case of emergency. Energy Environ. Sci. 2013, 6, 2124-2133. 
(43) Wain, A. J.; Wildgoose, G. G.; Heald, C. G. R.; Jiang, L.; Jones, T. G. J.; Compton, R. G. Electrochemical ESR and Voltammetric Studies of Lithium Ion Pairing with Electrogenerated 9,10Anthraquinone Radical Anions Either Free in Acetonitrile Solution or Covalently Bound to Multiwalled Carbon Nanotubes. J. Phys. Chem. B 2005, 109, 3971-3978.

(44) Bu, P.; Liu, S.; Lu, Y.; Zhuang, S.; Wang, H.; Tu, F. Effects of Carbon Black on the Electrochemical Performance of LithiumOrganic Coordination Compound Batteries. Int. J. Electrochem. Sci. 2012, 7, 4617-4624. 